Rev. Adm. Saúde Vol. 17, № 68, Jul. - Set. 2017

http://dx.doi.org/10.23973/ras.68.44

ARTIGO ORIGINAL

\title{
Auditoria de contas ambulatoriais no Sistema Único de Saúde no estado do Piauí
}

Audit of outpatient medical accounts in brazilian public health system in state of Piaui

\section{Djalma Ribeiro Costa ${ }^{1}$}

1. Médico, pós-graduado em estatística pela UFPI. Urologista pediátrico no Hospital Infantil Lucídio Portella, Teresina - PI

\section{RESUMO}

Introdução: o acesso universal, integral e igual à saúde depende de controle e fiscalização da produção da atenção à saúde no Sistema Único de Saúde, principalmente na atenção ambulatorial, porquanto é a partir dela que surgem todas as demais necessidades de investimento no setor saúde. Conhecer os pormenores da produção ambulatorial permite entender como se dá o financiamento do setor saúde e a eficácia das políticas públicas voltadas para o setor. Objetivo: conhecer a evolução histórica da produção ambulatorial no SUS no estado do Piauí. Metodologia: Realizou-se uma análise de série temporal da produção ambulatorial no estado do Piauí de modo global e estratificado através de informações disponíveis no DATASUS. Resultados e discussão: Encontrou-se uma produção com tendência histórica crescente sugerindo eficácia cumulativa da auditoria de contas no SUS, porém com alguns achados adversos como maior produção de alta complexidade, por atendimentos de urgência e por agravos externos e concentração da produção no Colegiado Intergestor Regional do Entre Rios, onde está a capital do estado. Conclusão: a produção ambulatorial no SUS no estado do Piauí tem apresentado tendência crescente, porém com fatores adversos gerenciais.

Palavras-chave: Auditoria administrativa. Sistema Único de Saúde. Assistência ambulatorial. Informática médica. 


\begin{abstract}
Introduction: universal access and integral and equal health care depend on controlling and supervision of the health assistance production in the Unified Health System (brazilian SUS - Sistema Único de Saúde), mainly in ambulatory care, because it is the source of the investments from which all sector needs arise. Knowing the details of the ambulatory assistance production allows to understand how the financing of the health sector and the effectiveness of public policies for this sector work. Objective: to know the historical evolution of the ambulatory assistance production in the UHS in the State of Piauí. Methodology: a time series analysis of total and stratified ambulatory assistance production in the state of Piauí through medical informatics available on the DATASUS. Results and discussion: growing historical trends were found, suggesting cumulative efficiency of management audit of accounts in the UHS, however with some adverse findings as greater production of high complexity assistance, emergency and external lesions care and concentration of production in the Intergestor Regional Collegiate of Entre Ríos, where the capital of the State is. Conclusion: the ambulatory production in the UHS in the State of Piauí has presented growing trends, but with adverse managerial factors.
\end{abstract}

Keywords: Management audit. Brazilian Unified Health System. Ambulatory care. Medical informatics.

\title{
INTRODUÇÃO
}

O Sistema Único de Saúde (SUS) tem passado por um longo processo de adequação de suas políticas de saúde, visando substancialmente a operacionalização de suas leis orgânicas (8080/90 e 8192/90) através de vários dispositivos legais e infralegais.

Este sistema de saúde visa, primordialmente, a universalização, a integralidade e a equidade, isto é, o acesso universal, a atenção à saúde desde a prevenção até a recuperação bem como o atendimento em todos os níveis de complexidade e a igualdade na prioridade de atenção à saúde às populações sob sua cobertura, isto é, todos aqueles que vivem no território brasileiro.

Os mecanismos de acessibilidade à assistência integral à saúde têm no atendimento ambulatorial sua relevância fulcral, pois é no atendimento ambulatorial da atenção primária em que a maior parte dos problemas de saúde são resolvidos com tecnologia leve à leve-dura.

Somente os problemas de saúde mais complexos é que requerem o atendimento em níveis de complexidade ascendentes (média e alta complexidade). 
Com a implementação de sistemas de controle e fiscalização, bem como com os sistemas de informação em saúde, os avanços nas políticas de planejamento e financiamento do setor saúde têm-se tornado promissores com impacto importante sobre os indicadores de qualidade de acesso no SUS.

Dentre os sistemas de controle e fiscalização no SUS, destaca-se o sistema nacional de auditoria que visa fortalecer a gestão do SUS, contribuindo para a alocação e utilização adequada dos recursos, a garantia de acesso e a qualidade da atenção à saúde oferecida aos seus usuários.

Do ponto de vista ambulatorial, o principal sistema de informação é o SIA-SUS (Sistema de Informação Ambulatorial) que oferece através de dados públicos a produção ambulatorial em todos os estados e municípios com todos os estratos relacionados às características da atenção à saúde no SUS (tipo de financiamento, nível de complexidade, Colegiado Intergestor Regional, tipo de aprovação das contas e o caráter do atendimento).

As ferramentas de informação e controle permitem ao gestor tomada de decisão, e conhecer a evolução história da produção ambulatorial e suas características é relevante para entender as tendências e as prioridade na alocação de recursos, facilitando à gestão em saúde traçar planos de saúde voltados para as prioridades em saúde pública.

\section{OBJETIVO}

Conhecer a evolução histórica da produção ambulatorial no SUS no estado do Piauí.

\section{MATERIAL E MÉTODOS}

Realizou-se um estudo de série temporal através dos dados obtidos de bases de dados públicos disponibilizadas na página eletrônica do Departamento de informática do SUS no Link 'acesso à informação', 'TABNET' e 'Assistência à saúde'.

Análise de série temporal foi realizada através do software MINITAB 17, utilizando-se de estatística descritiva e estatística paramétrica e nãoparamétrica, considerando estatisticamente significante um valor $p$ menor de 0,5 .

As variáveis estudadas foram contas apresentadas e contas aprovadas na produção ambulatorial do estado do Piauí no período de 2008 a 2016 segundo o caráter do atendimento (eletivo, urgência, acidente no local de trabalho ou a serviço da empresa, acidente no trajeto para o trabalho, outros tipos de acidente de trânsito e outros tipos de lesões ou envenenamentos), tipo de financiamento ambulatorial [atenção básica (PAB), assistência farmacêutica, fundo de ações estratégicas e compensações (FAEC), Média e alta complexidade (MAC), incentivo MAC, vigilância em saúde e gestão do SUS], 
segundo o nível de complexidade (atenção básica e média e alta complexidades) e segundo a região de saúde pelo colegiado intergestor regional (CIR) (Carnaubais, Chapada das Mangabeiras, Cocais, Entre Rios, Planície Litorânea, Serra da Capivara, Tabuleiros Alto Parnaíba, Vale do Canindé, Vale dos Rios Guaribas, Vale do Sambito, Vale Rio Piauí/ltaueiras e ignorado).

Por tratar-se de dados públicos, não se fez necessária a aprovação prévia do comitê de ética em pesquisa pela Resolução n510 de 07 de abril de 2016.

\section{RESULTADOS}

\section{No estado do Piauí}

No período de janeiro de 2008 a dezembro de 2016, foram, em média, apresentadas 4.042.065 contas, das quais, em média, 3.543.974 aprovadas/ano. A distribuição dos dados para contas apresentadas e aprovadas aceita a normalidade (Figuras 1 a 2) e apresentaram tendência crescente ao longo deste intervalo (Figuras 4 e 5).

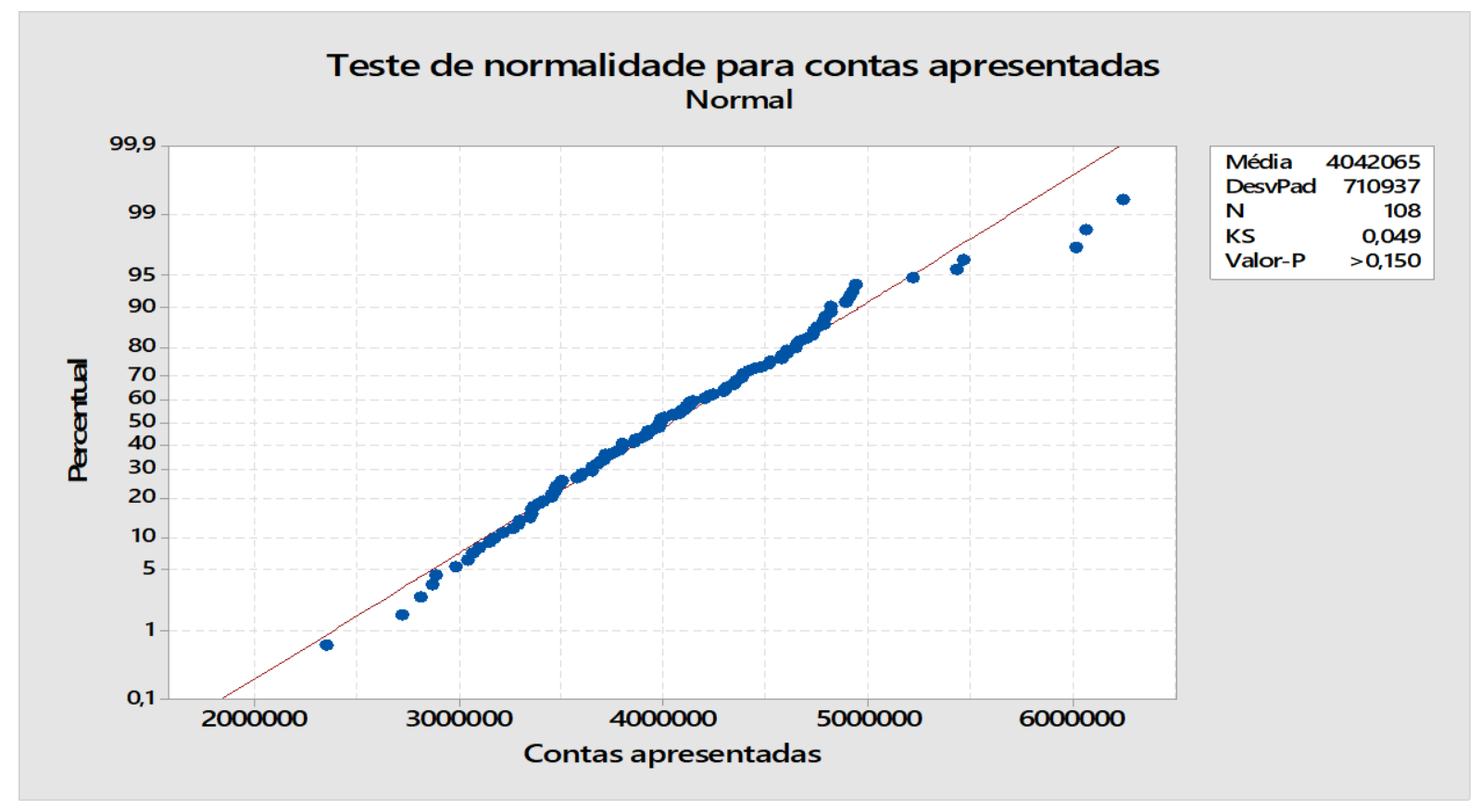

Figura 1. Distribuição das contas ambulatoriais apresentadas de 2008 a 2016. Abreviaturas: DesvPad é o desvio-padrão, N é o tamanho da amostra e KS é o teste de Kolmogorov-Smirnov ( $p$-valor maior de $5 \%$ aceita a normalidade). Fonte: DATASUS, 2017. 


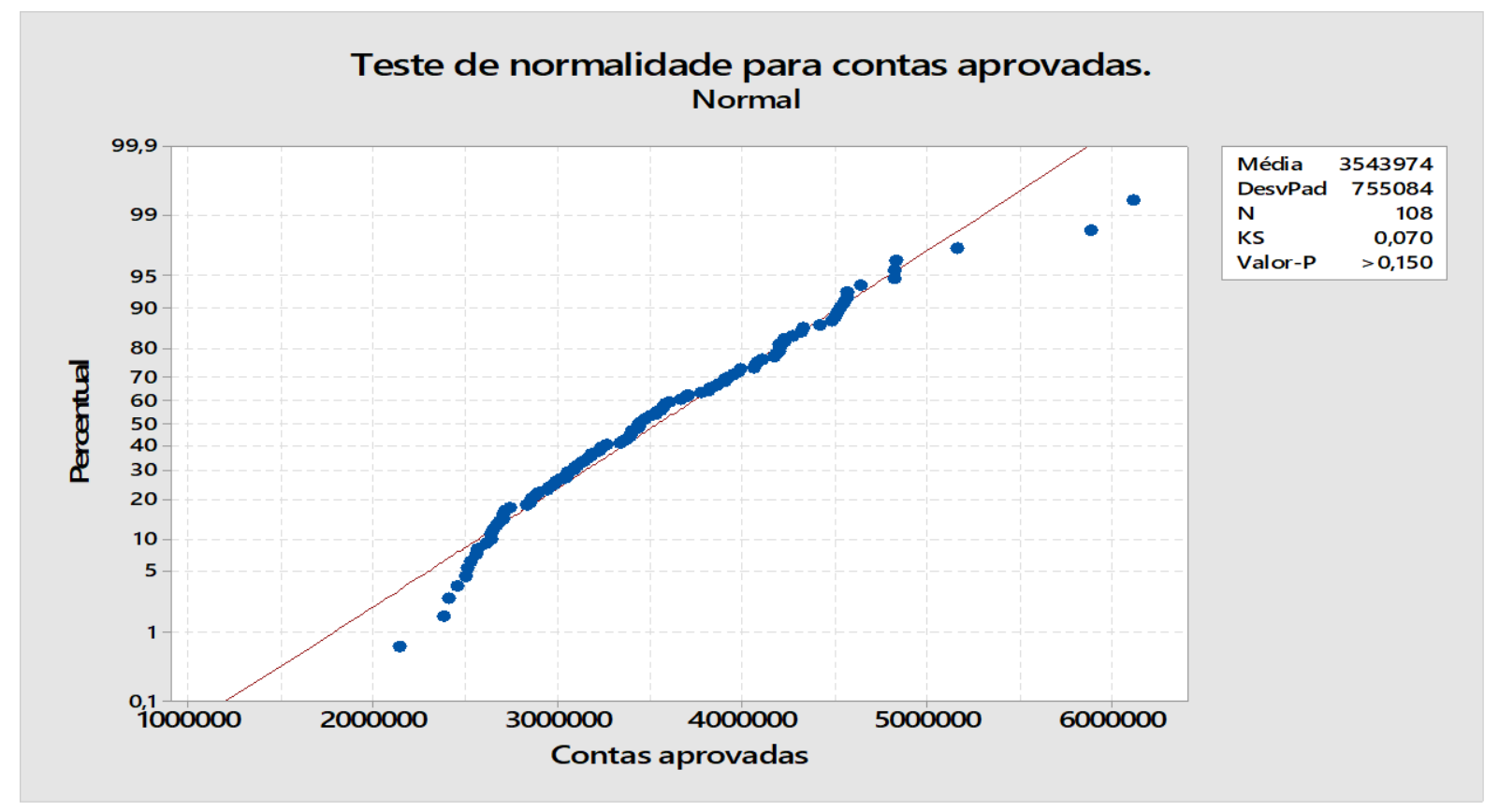

Figura 2. Distribuição das contas ambulatoriais aprovadas de 2008 a 2016. Abreviaturas: DesvPad é o desvio-padrão, N é o tamanho da amostra e KS é o teste de Kolmogorov-Smirnov ( $p$-valor maior de $5 \%$ aceita a normalidade). Fonte: DATASUS, 2017.

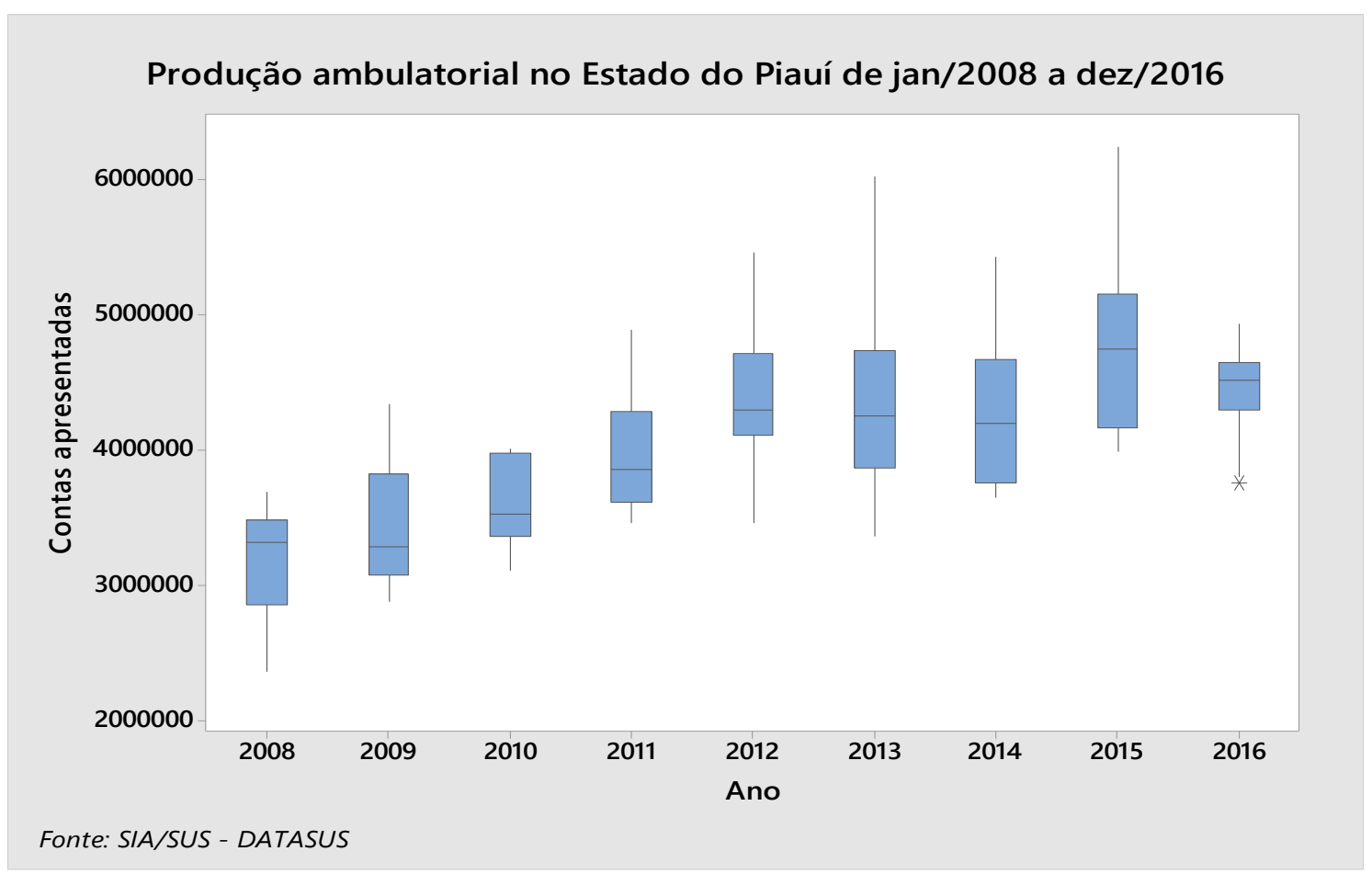

Figura 3. Tendência crescente das contas ambulatoriais apresentadas de 2008 a 2016. Fonte: DATASUS, 2017. 


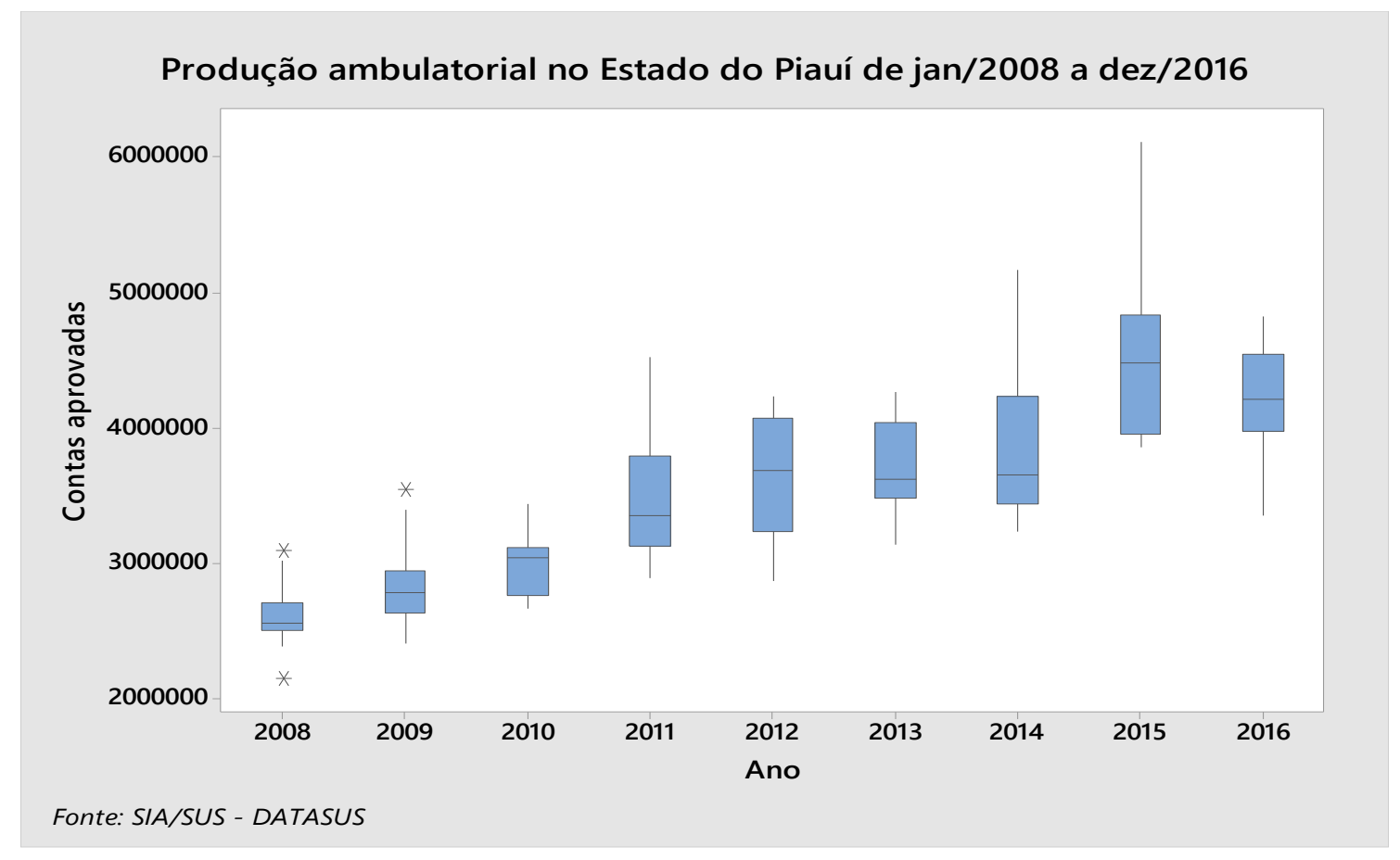

Figura 4. Tendência crescente das contas ambulatoriais aprovadas de 2008 a 2016. Fonte: DATASUS, 2017.

Através de análise de variância, foi possível verificar que a distribuição crescente da produção ambulatorial ao longo do intervalo de estudo segundo o ano foi estatisticamente significante ( $p$-valor $<0,0001$ ) tanto à produção apresentada (tabela 1) quanto à produção aprovada (tabela 2).

Tabela 1. Contas apresentadas da produção ambulatorial no estado do Piauí de janeiro de 2008 a dezembro de 2016 no SIA/SUS.

\begin{tabular}{lllll}
\hline Ano & N & Média & $\begin{array}{l}\text { Desvio- } \\
\text { padrão }\end{array}$ & $\begin{array}{l}\text { Agrupamento } \\
\text { Método de } \\
\text { Tukey }\end{array}$ \\
\hline $\mathbf{2 0 0 8}$ & 12 & 3.186 .681 & 406.685 & A \\
$\mathbf{2 0 0 9}$ & 12 & 3.416 .306 & 457.131 & A B \\
$\mathbf{2 0 1 0}$ & 12 & 3.593 .990 & 329.645 & A B \\
$\mathbf{2 0 1 1}$ & 12 & 3.980 .804 & 457.312 & B C \\
$\mathbf{2 0 1 2}$ & 12 & 4.352 .999 & 514.549 & C D \\
$\mathbf{2 0 1 3}$ & 12 & 4.337 .422 & 693.079 & C D
\end{tabular}




\begin{tabular}{lllll}
$\mathbf{2 0 1 4}$ & 12 & 4.272 .298 & 543.549 & C D \\
$\mathbf{2 0 1 5}$ & 12 & 4.821 .841 & 732.260 & D \\
$\mathbf{2 0 1 6}$ & 12 & 4.416 .244 & 352.876 & C D \\
\hline Total & $\mathbf{1 0 8}$ & $\mathbf{4 . 0 4 2 . 0 6 5}$ & $\mathbf{7 1 0 . 9 3 7}$ &
\end{tabular}

Legenda: Método de Tukey é o teste post-hoc utilizado após análise de variância para identificar quais anos tem produção diferente entre si. Médias que não compartilham uma letra são significativamente diferentes. ${ }^{a}$ Refere-se ao ano do processamento. Fonte: DATASUS, 2017.

Tabela 2. Contas aprovadas da produção ambulatorial no estado do Piauí de janeiro de 2008 a dezembro de 2016 no SIA/SUS.

\begin{tabular}{lllll}
\hline Ano & N & Média & $\begin{array}{l}\text { Desvio- } \\
\text { padrão }\end{array}$ & $\begin{array}{l}\text { Agrupamento } \\
\text { Método de } \\
\text { Tukey }\end{array}$ \\
\hline $\mathbf{2 0 0 8}$ & 12 & 2.608 .749 & 254.662 & A \\
$\mathbf{2 0 0 9}$ & 12 & 2.831 .517 & 341.801 & A \\
$\mathbf{2 0 1 0}$ & 12 & 3.009 .979 & 249.547 & A B \\
$\mathbf{2 0 1 1}$ & 12 & 3.457 .436 & 478.304 & B C \\
$\mathbf{2 0 1 2}$ & 12 & 3.643 .170 & 443.295 & C D \\
$\mathbf{2 0 1 3}$ & 12 & 3.687 .221 & 368.701 & C D \\
$\mathbf{2 0 1 4}$ & 12 & 3.834 .125 & 571.868 & C D \\
$\mathbf{2 0 1 5}$ & 12 & 4.608 .183 & 740.261 & E \\
$\mathbf{2 0 1 6}$ & 12 & 4.215 .387 & 431.787 & D E \\
\hline Total & $\mathbf{1 0 8}$ & $\mathbf{3 . 5 4 3 . 9 7 4}$ & $\mathbf{7 5 5 . 0 8 4}$ & \\
\hline
\end{tabular}

Legenda: Método de Tukey é o teste post-hoc utilizado após análise de variância para identificar quais anos tem produção diferente entre si. Médias que não compartilham uma letra são significativamente diferentes. ${ }^{\text {a }}$ Refere-se ao ano do processamento. Fonte: DATASUS, 2017.

Através de análise de série temporal, é possível comprovar uma tendência e uma sazonalidade na produção ambulatorial apresentada no estado do Piauí. O modelo que melhor se ajustou através dos erros é o quadrático ( $\mathrm{Yt}=$ $\left.2891311+33115 \times t-165,9 \times t^{\wedge} 2\right)$ (Figura 5). 
Para o estudo da sazonalidade, optou-se pelo modelo aditivo cuja equação linear ajustada foi $Y t=3219066+15101 \times t$, sendo utilizado para realizar a decomposição, permitindo descobrir os meses em que ocorrem melhor produção através dos índices sazonais (Figura 6).

Segundo os índices sazonais, foi possível constatar o aumento na produção ambulatorial apresentada em janeiro (1), maio (5), junho (6), setembro (9) e outubro (10) através de uma e. Os maiores incrementos medianos na produção ocorrem em outubro (10), setembro (9), maio (5), janeiro (1) e junho (6), respectivamente. Os maiores decréscimos na produção ocorrem em dezembro, março, abril e novembro, respectivamente (Figura 7).

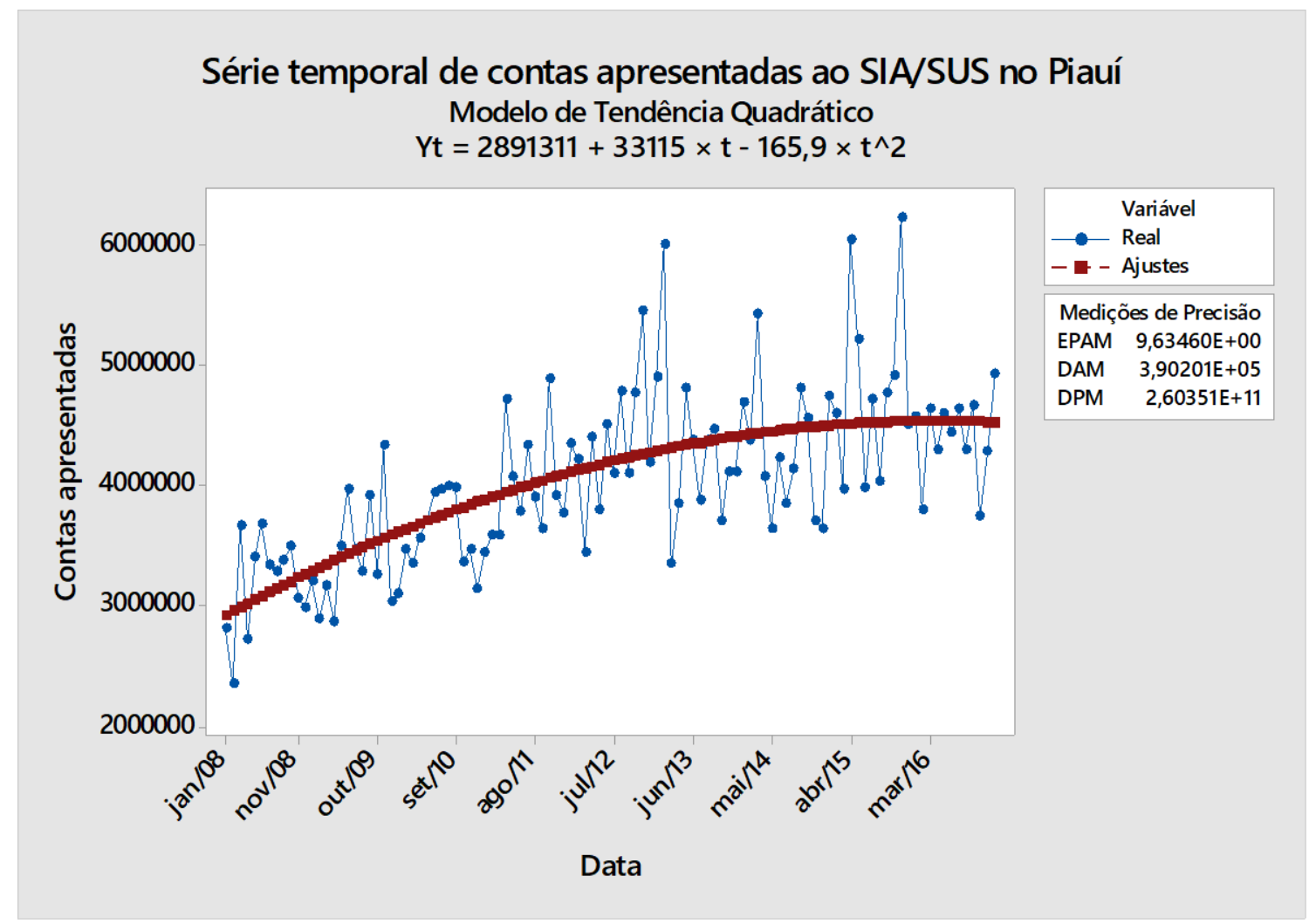

Figura 5. Modelo de série temporal com equação de ajuste para previsão. Fonte: DATASUS, 2017. 


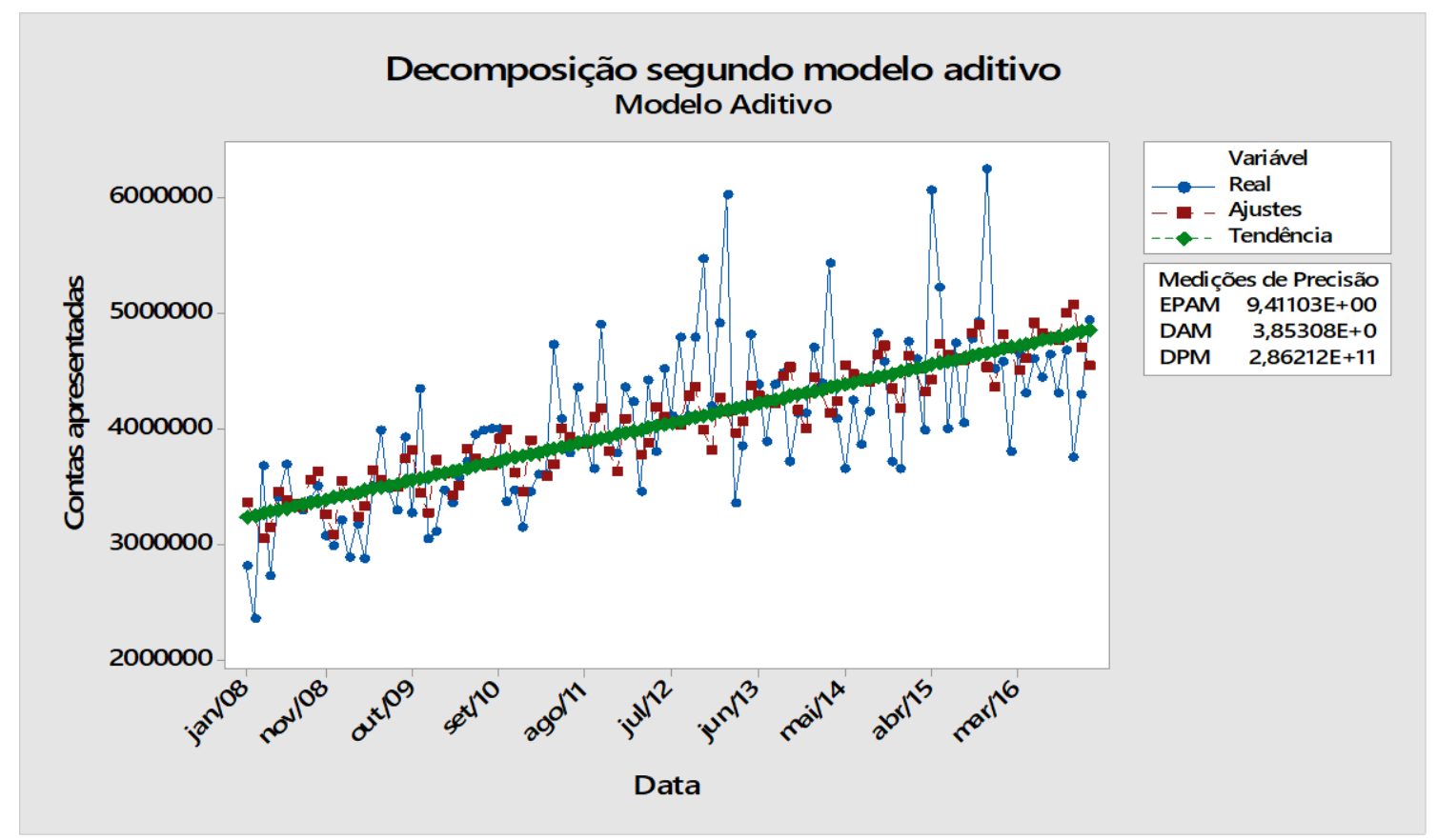

Figura 6. Modelo aditivo para decomposição para permitir o estudo de tendência e sazonalidade. Fonte: DATASUS, 2017.

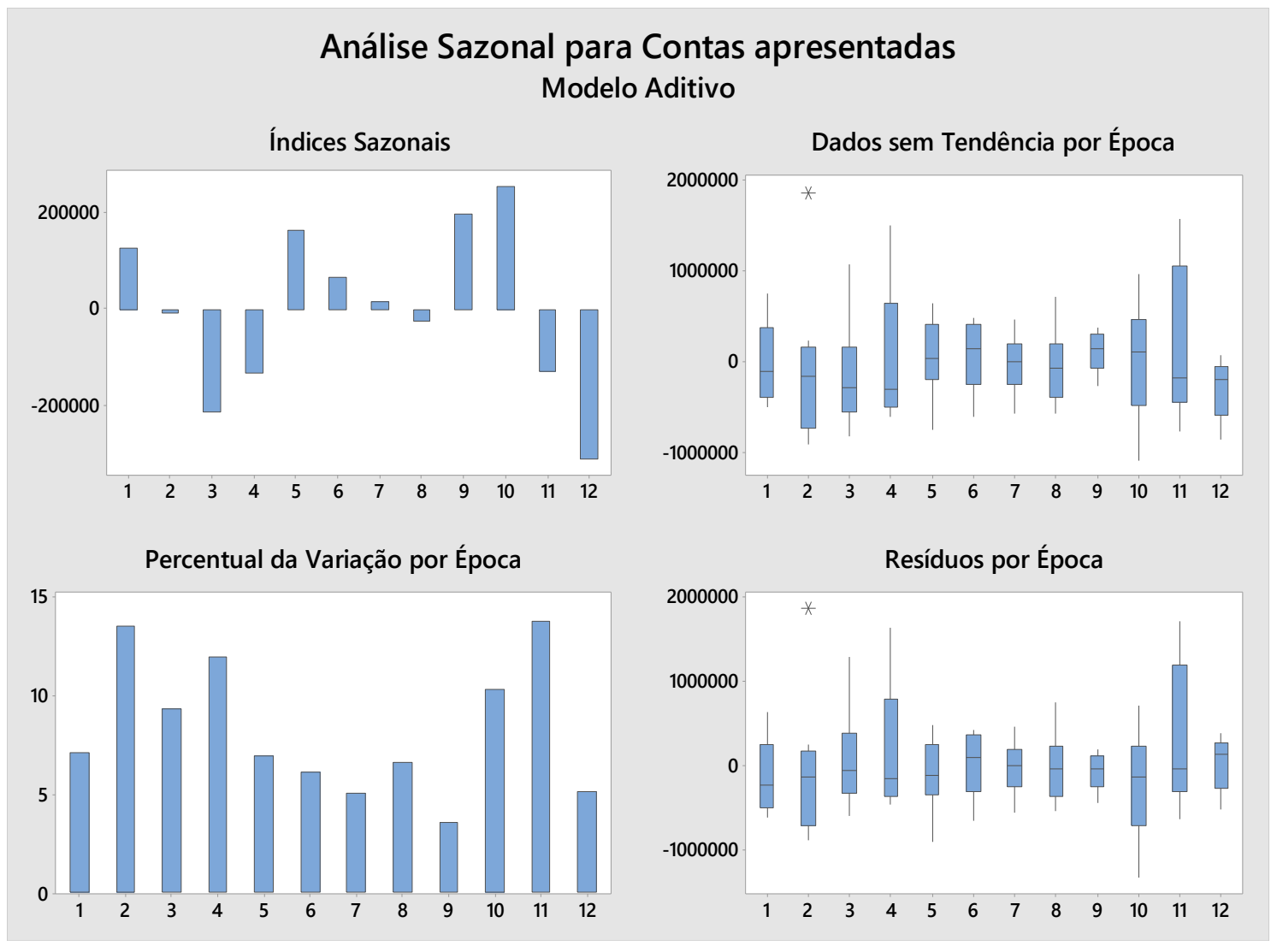

Figura 7. Análise sazonal das contas apresentadas no estado do Piauí de 2008 a 2016. Fonte: DATASUS, 2017. 
Em relação às contas aprovadas, também foi possível obter uma equação para previsão, sendo o modelo exponencial o que melhor se ajustou aos erros [Yt $=$ $\left.2584393 \times\left(1,00541^{\wedge} \mathrm{t}\right)\right]$ (Figura 8).

Para decomposição e estudar sazonalidade, utilizou-se o modelo aditivo cuja equação linear ajustada foi $\mathrm{Yt}=2512028+18935 \times \mathrm{t}$ (Figura 9).

Segundo os índices sazonais através deste modelo aditivo, foi possível constatar o aumento na produção ambulatorial aprovada em janeiro (1), abril (4), junho (6), setembro (9) e novembro (11). Os maiores incrementos em contas aprovadas ocorrem em junho (6), janeiro (1), novembro (11) e abril (4), respectivamente. Os maiores decréscimos na produção aprovada ocorrem em dezembro (12), fevereiro (2), março (3), outubro (10) e maio (5), respectivamente (Figura 10).

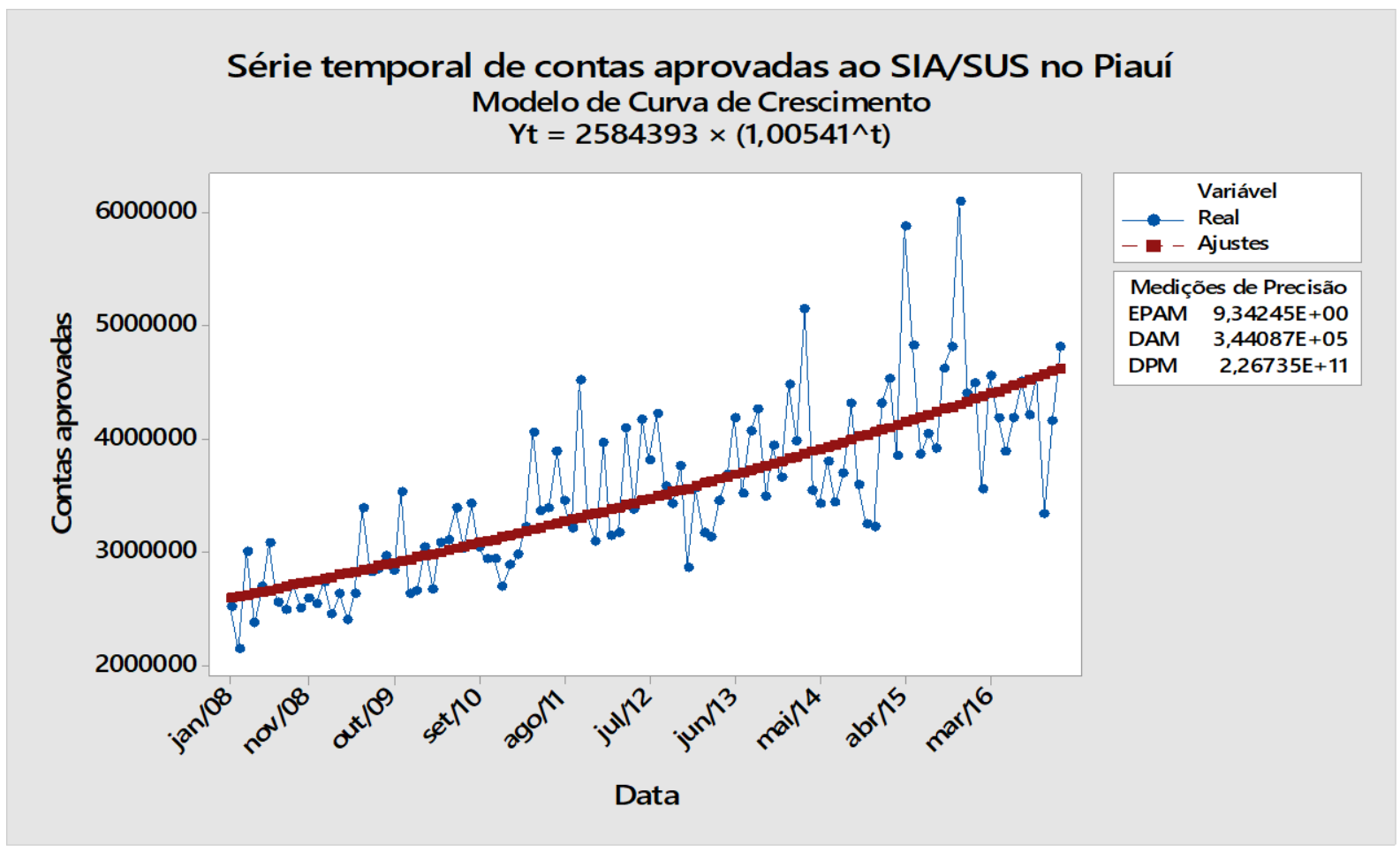

Figura 8. Série temporal para previsão de produção aprovada no período de 2008 a 2016. Fonte: DATASUS, 2017. 


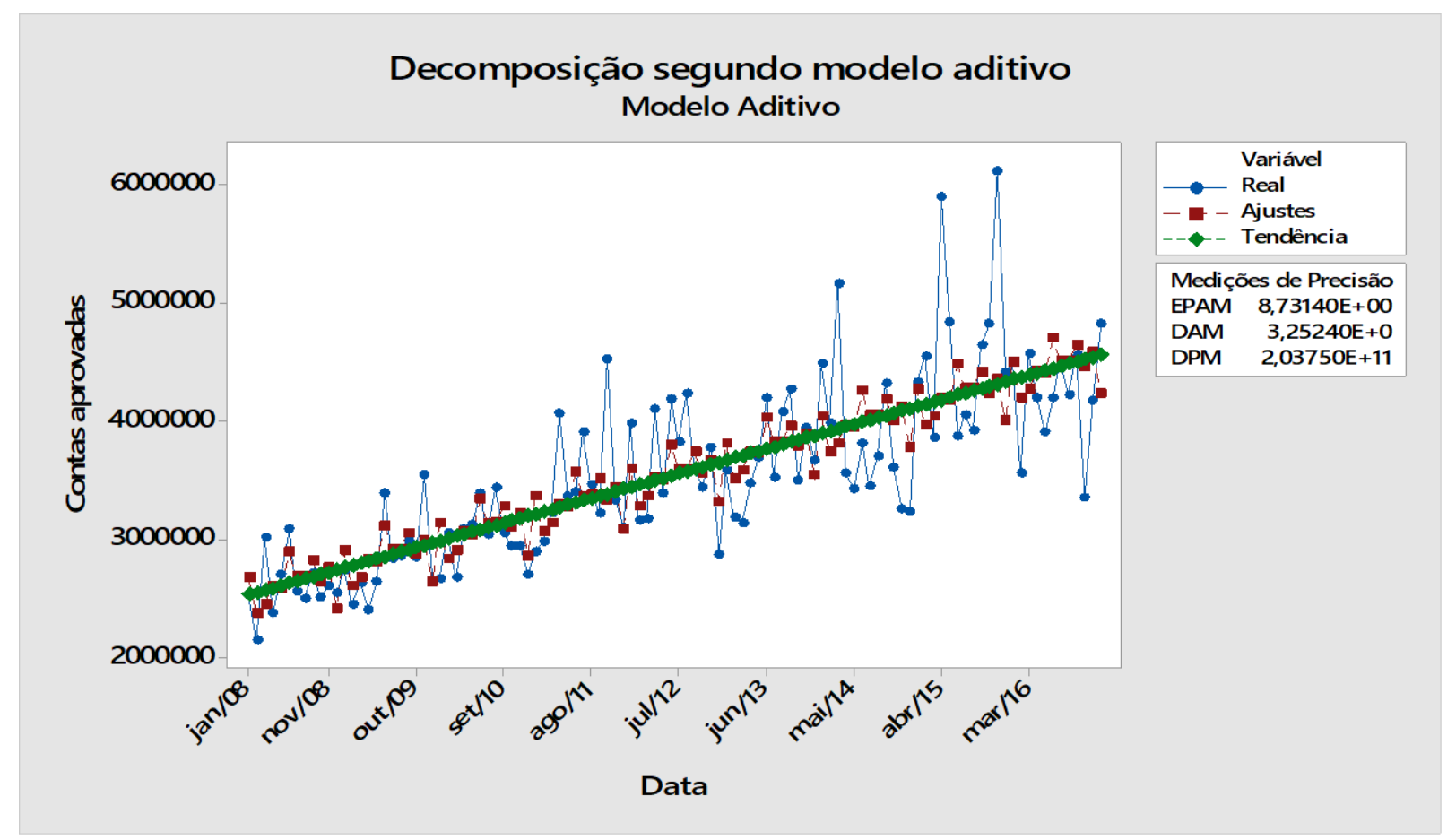

Figura 9. Modelo aditivo de decomposição para permitir o estudo de tendência e sazonalidade. Fonte: DATASUS, 2017.

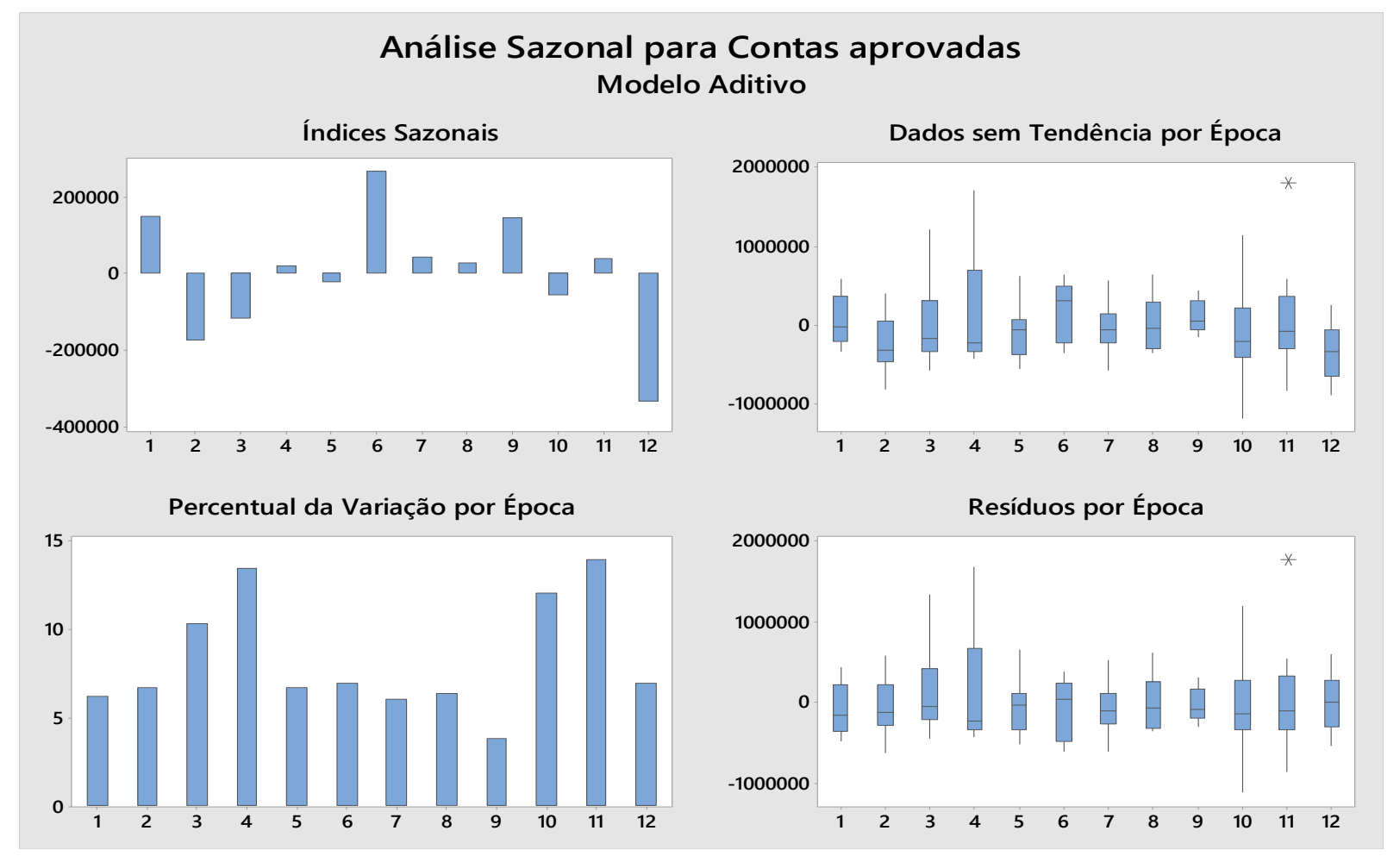

Figura 10. Análise sazonal das contas aprovadas no estado do Piauí de 2008 a 2016. Fonte: DATASUS, 2017. 
Portando, foi possível observar uma tendência crescente comprovado através de modelos matemáticos com um padrão sazonal muito parecido entre as contas apresentadas e aprovadas.

\section{Quanto ao tipo de aprovação das contas}

Observa-se historicamente neste estudo de 10 anos que as contas totalmente aprovadas cresceram em números absolutos e que foi possível através de curvas de tendência de série temporal demonstrar ser crescente para contas totalmente aprovadas e decrescente para contas parcialmente aprovadas e isto foi estatisticamente significante ( $p$-valor $<0,0001)$, sugerindo eficácia cumulativa na cobrança e na fiscalização das contas (Figuras 11 a $13 \mathrm{e}$ Tabelas 3 e 4).

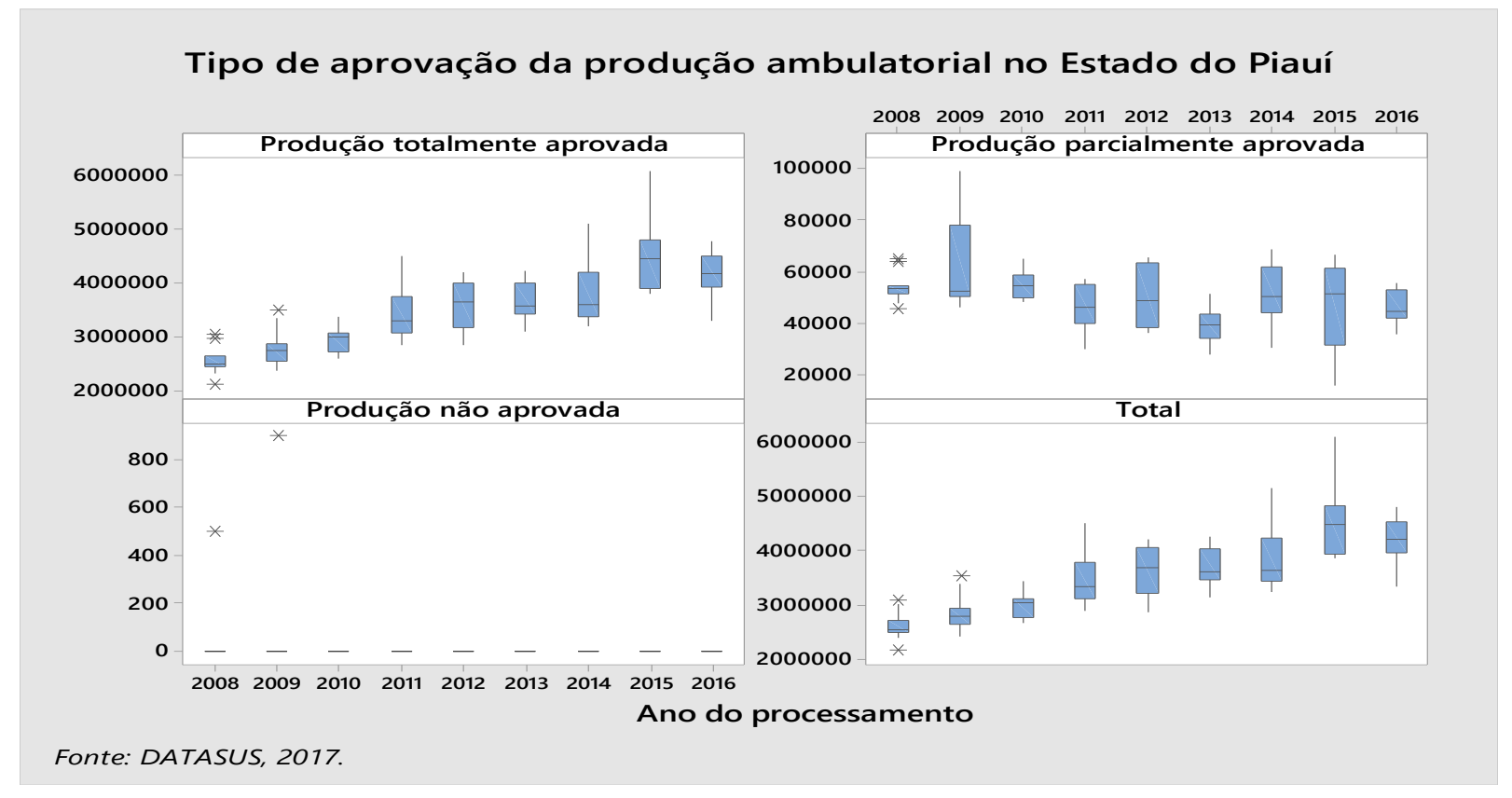

Figura 11. Distribuição da produção entre 2008 a 2016 segundo o tipo de aprovação. Fonte: DATASUS, 2017.

Tabela 3. Contas totalmente aprovadas da produção ambulatorial no estado do Piauí.

\begin{tabular}{lllll}
\hline Ano & N & Média & $\begin{array}{l}\text { Desvio- } \\
\text { padrão }\end{array}$ & $\begin{array}{l}\text { Agrupamento } \\
\text { Método de } \\
\text { Tukey }\end{array}$ \\
\hline $\mathbf{2 0 0 8}$ & 12 & 2.554 .857 & 255.041 & A \\
$\mathbf{2 0 0 9}$ & 12 & 2.768 .288 & 34.637 & A \\
\hline
\end{tabular}




\begin{tabular}{lllll}
$\mathbf{2 0 1 0}$ & 12 & 2.954 .979 & 251.301 & A B \\
$\mathbf{2 0 1 1}$ & 12 & 3.410 .847 & 485.410 & B C \\
$\mathbf{2 0 1 2}$ & 12 & 3.592 .675 & 443.114 & C D \\
$\mathbf{2 0 1 3}$ & 12 & 3.648 .041 & 365.793 & C D \\
$\mathbf{2 0 1 4}$ & 12 & 3.782 .949 & 572.371 & C D \\
$\mathbf{2 0 1 5}$ & 12 & 4.561 .675 & 747.492 & E \\
$\mathbf{2 0 1 6}$ & 12 & 4.168 .941 & 432.532 & D E \\
\hline Total & $\mathbf{1 0 8}$ & $\mathbf{3 . 4 9 3 . 6 9 5}$ & $\mathbf{7 5 9 . 8 8 0}$ &
\end{tabular}

Legenda: Método de Tukey é o teste post-hoc utilizado após análise de variância para identificar quais anos tem produção diferente entre si. Médias que não compartilham uma letra são significativamente diferentes. ${ }^{a}$ Refere-se ao ano do processamento. Fonte: DATASUS, 2017.

Tabela 4. Contas parcialmente aprovadas da produção ambulatorial no estado do Piauí.

\begin{tabular}{lllll}
\hline Ano $^{\mathbf{a}}$ & $\mathbf{N}$ & Média & $\begin{array}{l}\text { Desvio- } \\
\text { padrão }\end{array}$ & $\begin{array}{l}\text { Agrupamento } \\
\text { Método de } \\
\text { Tukey }\end{array}$ \\
\hline $\mathbf{2 0 0 8}$ & 12 & 53.851 & 5.557 & A B \\
$\mathbf{2 0 0 9}$ & 12 & 63.154 & 18.397 & A \\
$\mathbf{2 0 1 0}$ & 12 & 55.000 & 5.336 & A B \\
$\mathbf{2 0 1 1}$ & 12 & 46.590 & 8.413 & B C \\
$\mathbf{2 0 1 2}$ & 12 & 50.495 & 11.466 & A B C \\
$\mathbf{2 0 1 3}$ & 12 & 39.180 & 6.491 & C \\
$\mathbf{2 0 1 4}$ & 12 & 51.176 & 11.380 & A B C \\
$\mathbf{2 0 1 5}$ & 12 & 46.509 & 17.036 & B C \\
$\mathbf{2 0 1 6}$ & 12 & 46.446 & 6.324 & B C \\
\hline Total & $\mathbf{1 0 8}$ & $\mathbf{5 0 . 2 6 7}$ & $\mathbf{1 2 . 4 2 9}$ & \\
\hline
\end{tabular}

Legenda: Método de Tukey é o teste post-hoc utilizado após análise de variância para identificar quais anos tem produção diferente entre si. Médias que não compartilham uma letra 
são significativamente diferentes. ${ }^{\text {a }}$ Refere-se ao ano do processamento. Fonte: DATASUS, 2017.

Através de análise de série temporal, observa-se uma tendência negativa para contas parcialmente aprovadas. A equação com melhor ajuste foi exponencial $\left(Y t=57193,7 \times\left(0,997060^{\wedge} t\right)\right.$. Por outro lado, para as contas totalmente aprovadas, a tendência é positiva, tendo uma equação exponencial também como a melhor fórmula de ajuste $\left(\mathrm{Yt}=2527829 \times\left(1,00554^{\wedge} \mathrm{t}\right)\right.$.

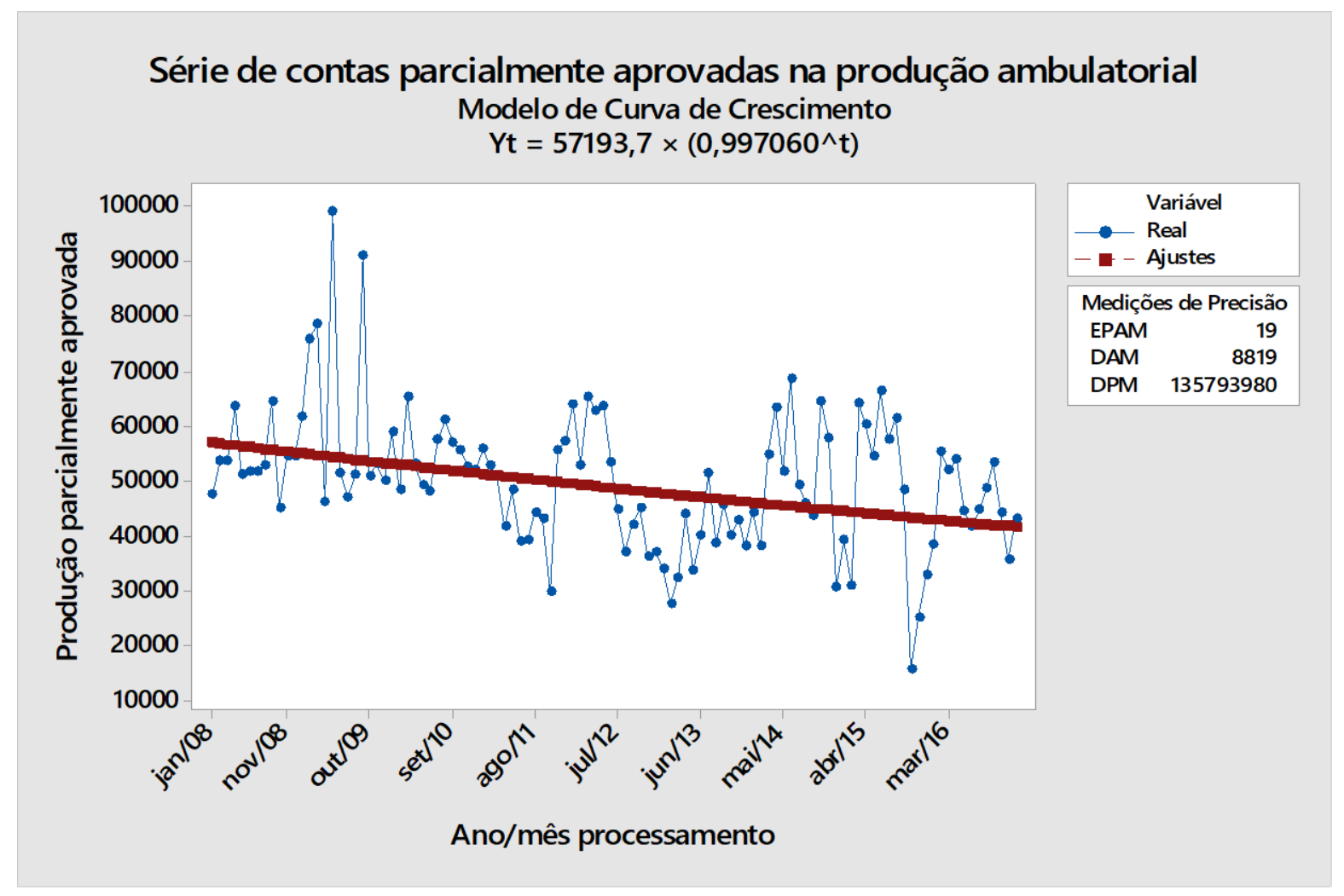

Figura 12. Curva de tendência histórica de produção ambulatorial totalmente aprovada. Fonte: DATASUS, 2017. 


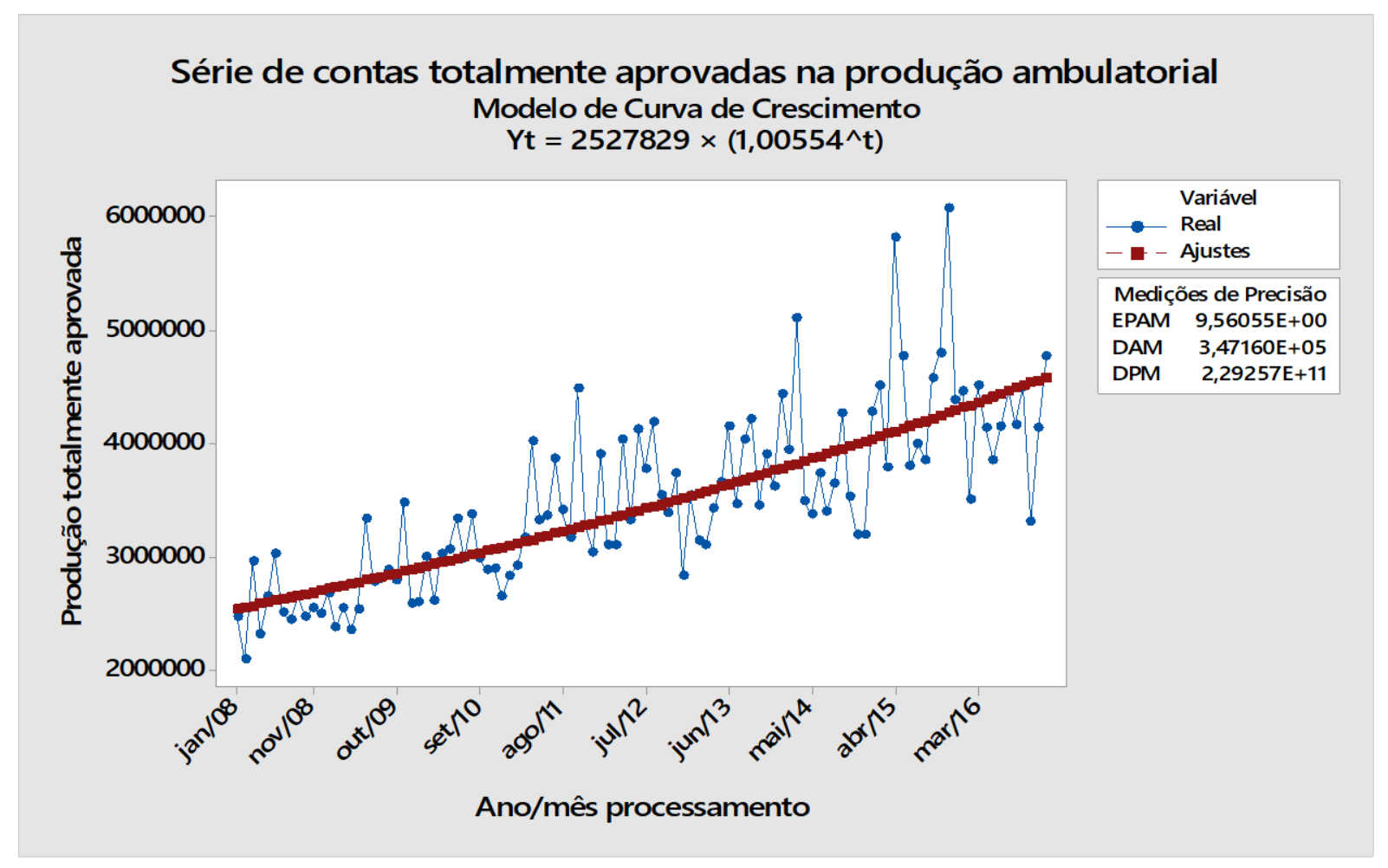

Figura 13. Curva de tendência história de produção ambulatorial parcialmente aprovada. Fonte: DATASUS, 2017.

\section{Segundo o caráter do atendimento}

Através do estudo do caráter de atendimento, é possível constatar quais os tipos de atendimento ambulatorial que foram os principais responsáveis pelo aumento da produção ambulatorial no estado do Piauí no período de 2008 a 2016.

Os atendimentos ambulatoriais eletivos, os de urgência, por acidentes de trânsito e outras lesões ou envenenamento foram os principais tipos que contribuíram com a produção estadual. De um modo negativo para as análises de produção, tem havido declaração de informação inexistente em números crescentes, interferindo numa análise real das condições de saúde e de assistência à população (Figuras 14 e 15). 
Produção ambulatorial estadual apresentada de 2008 a 2016 Conforme o caráter do atendimento

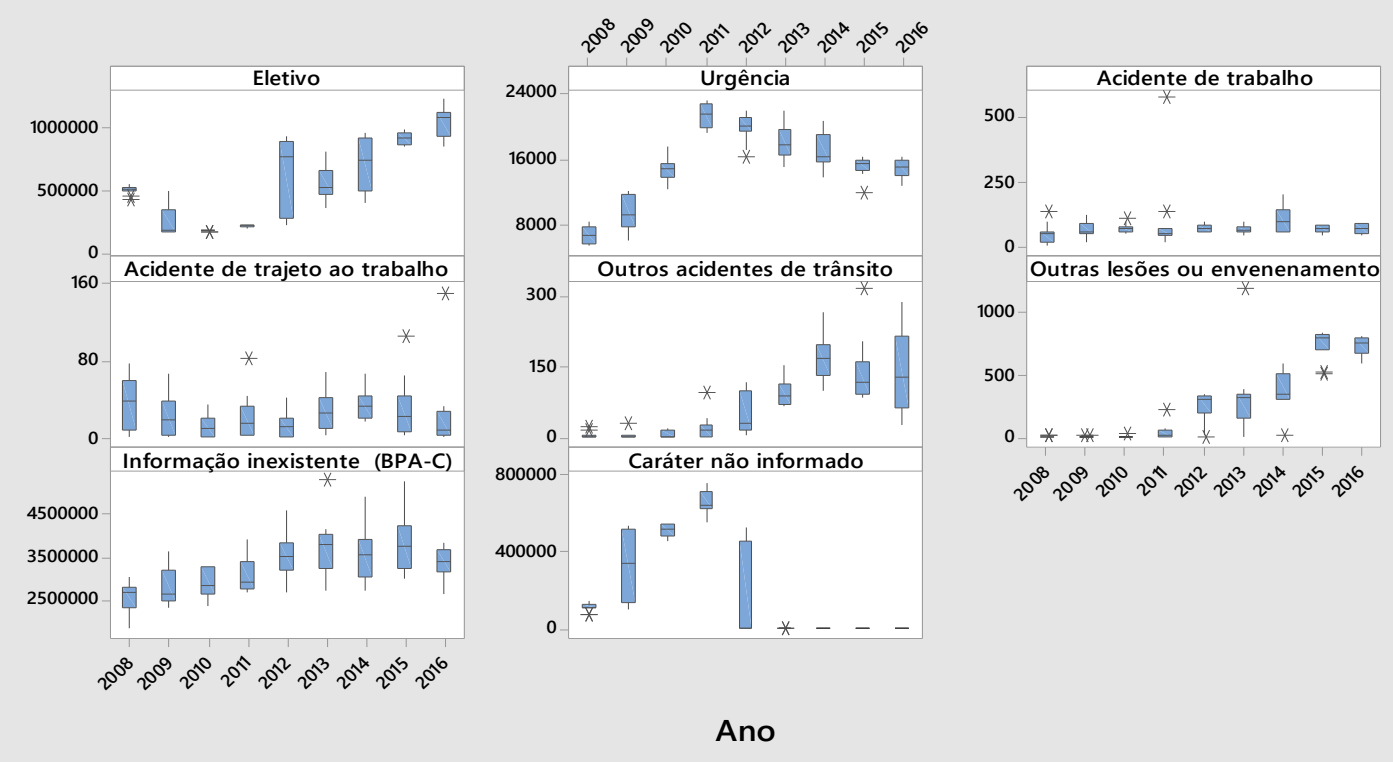

Fonte: DATASUS, 2017.

Figura 14. Distribuição da produção ambulatorial apresentada segundo o ano e o caráter da consulta. Dados analisados através do teste Kruskal Wallis (valor $p$ $<0,05)$. Fonte: DATASUS, 2017.

Produção ambulatorial estadual aprovada de 2008 a 2016 Conforme o caráter de atendimento

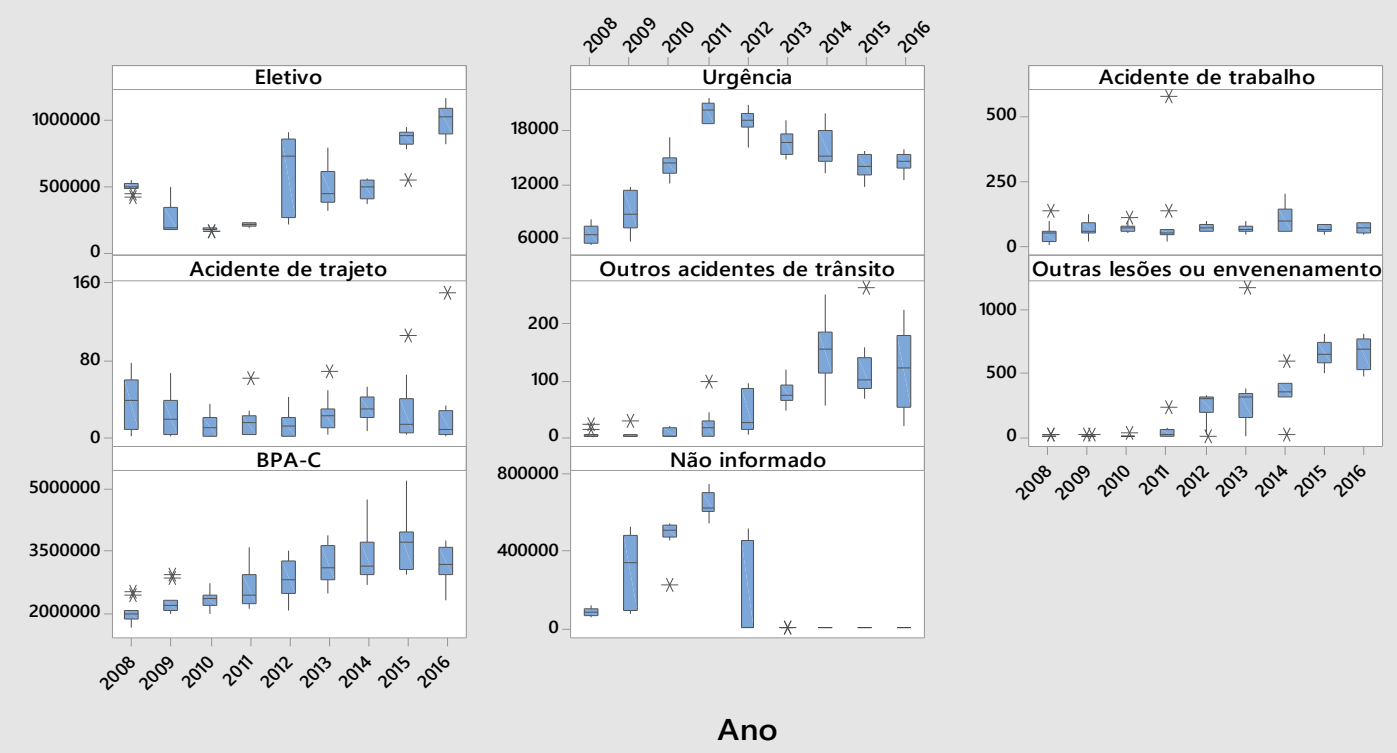

Fonte: DATASUS, 2017. 
Figura 15. Distribuição da produção ambulatorial aprovada segundo o ano e o caráter da consulta. Dados analisados através do teste Kruskal Wallis (valor $p$ $<0,05$, exceto para acidente de trajeto). Fonte: DATASUS, 2017.

\section{Segundo o tipo de financiamento ambulatorial}

O estudo do tipo de financiamento permite entender que, paralelamente ao aumento histórico da produção ambulatorial, programas de financiamento estratégico também tiveram incremento. Destacaram-se a assistência farmacêutica, o piso de atenção básica, o incentivo à média e à alta complexidade (MAC) e o próprio investimento à MAC, respectivamente (Figuras 16 e 17).

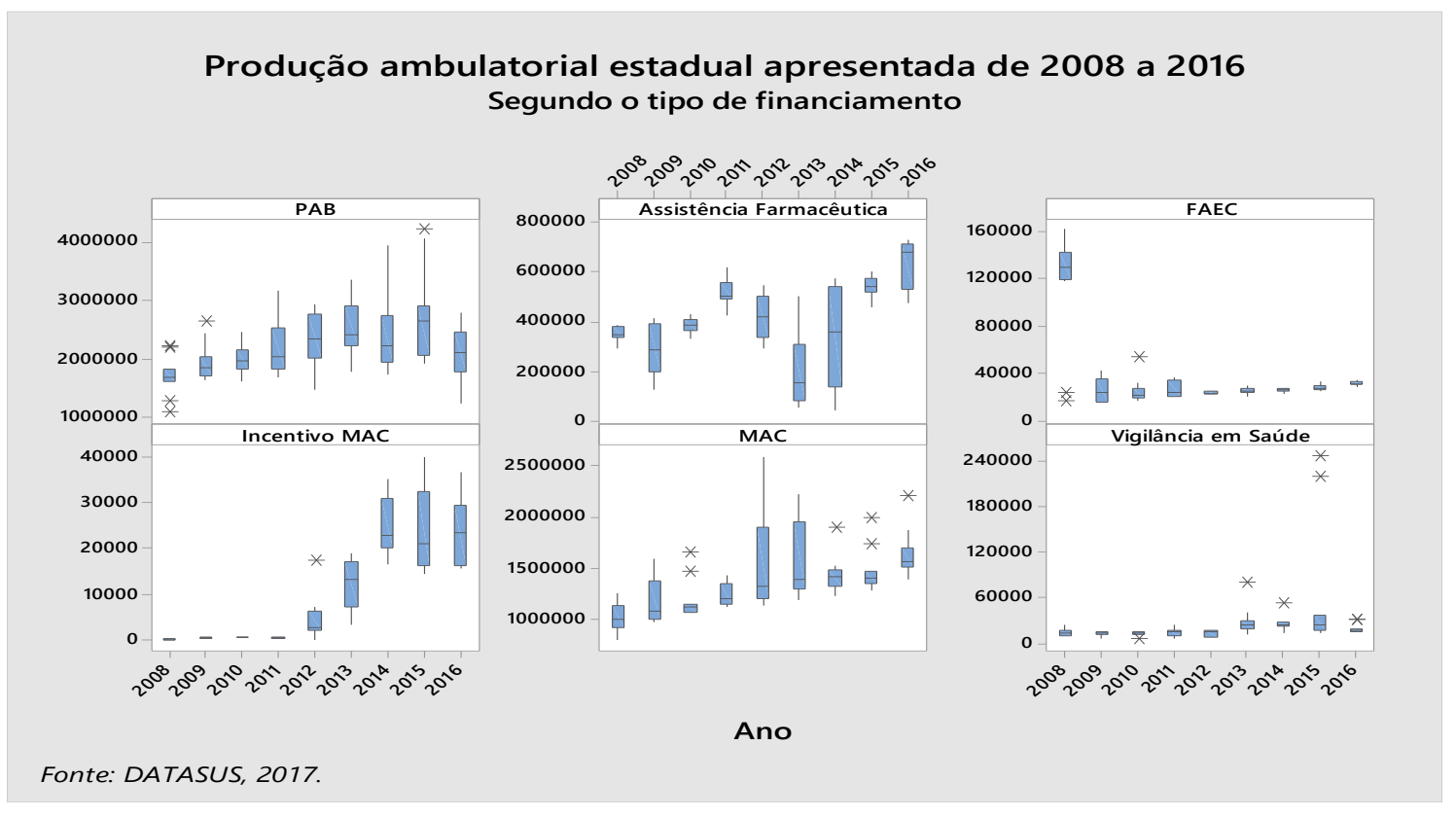

Figura 16. Distribuição da produção ambulatorial apresentada segundo o ano e o tipo de financiamento. Dados analisados através do teste Kruskal Wallis (valor $\mathrm{p}<0,0001$ ) para cada variável. Fonte: DATASUS, 2017. 


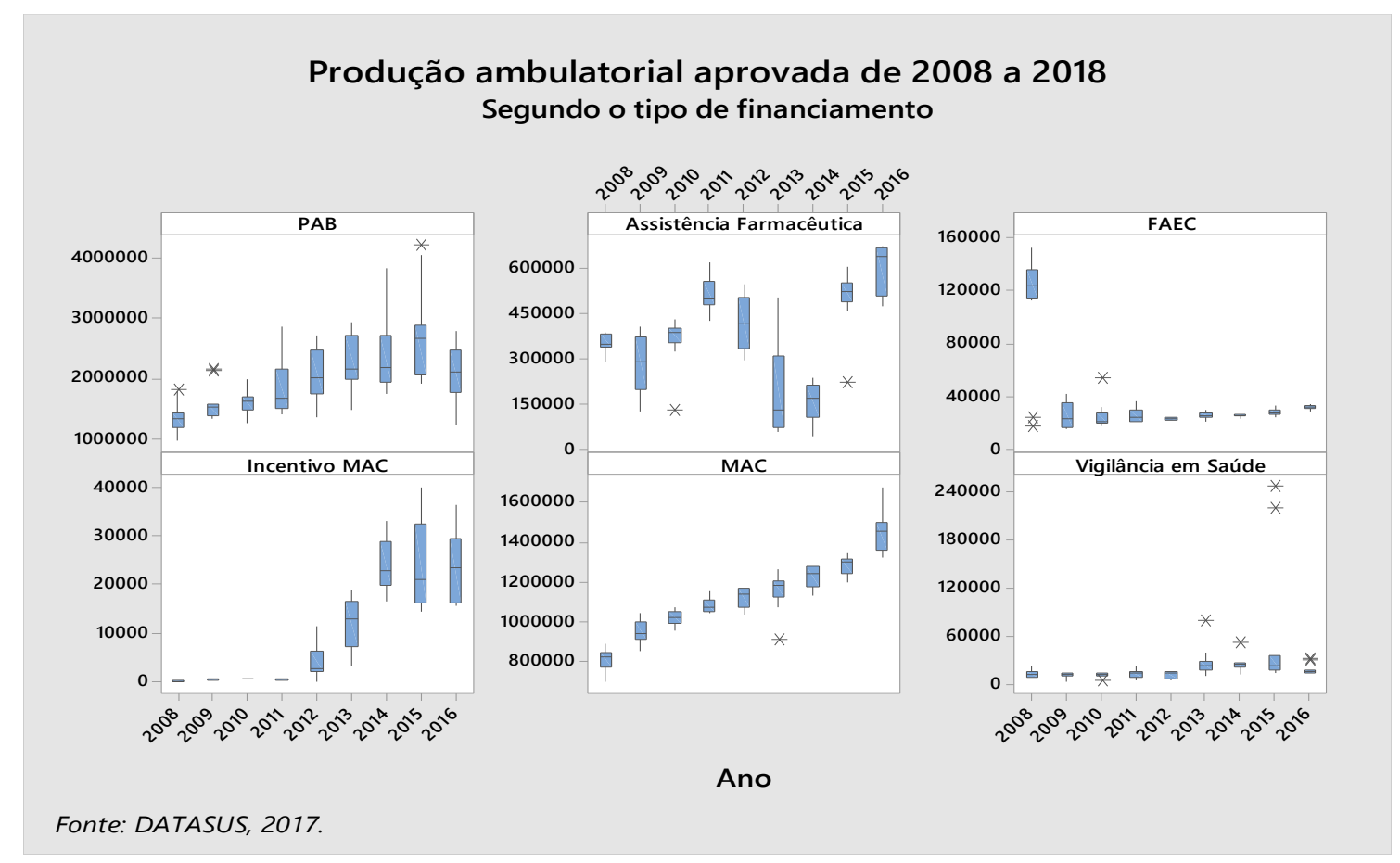

Figura 17. Distribuição da produção ambulatorial aprovada segundo o ano e o tipo de financiamento. Dados analisados através do teste Kruskal Wallis (valor $\mathrm{p}<0,0001)$ para cada variável. Fonte: DATASUS, 2017.

\section{Segundo o nível de complexidade}

Apesar da produção variar bastante ao longo do tempo segundo o nível de complexidade, a alta complexidade responde pelos maiores valores absolutos seguida pela atenção básica e média complexidade respectivamente, sugerindo uma maior procura pelos serviços de alta complexidade ao invés da atenção primária e da média complexidade, respectivamente (Figuras 18 e 19). Este fenômeno está consoante ao achado anterior de incremento histórico de financiamento próprio à MAC e incentivo à MAC. 


\section{Produção ambulatorial estatual apresentada de 2008 a 2016}

Segundo o nível de complexidade da atenção à saúde

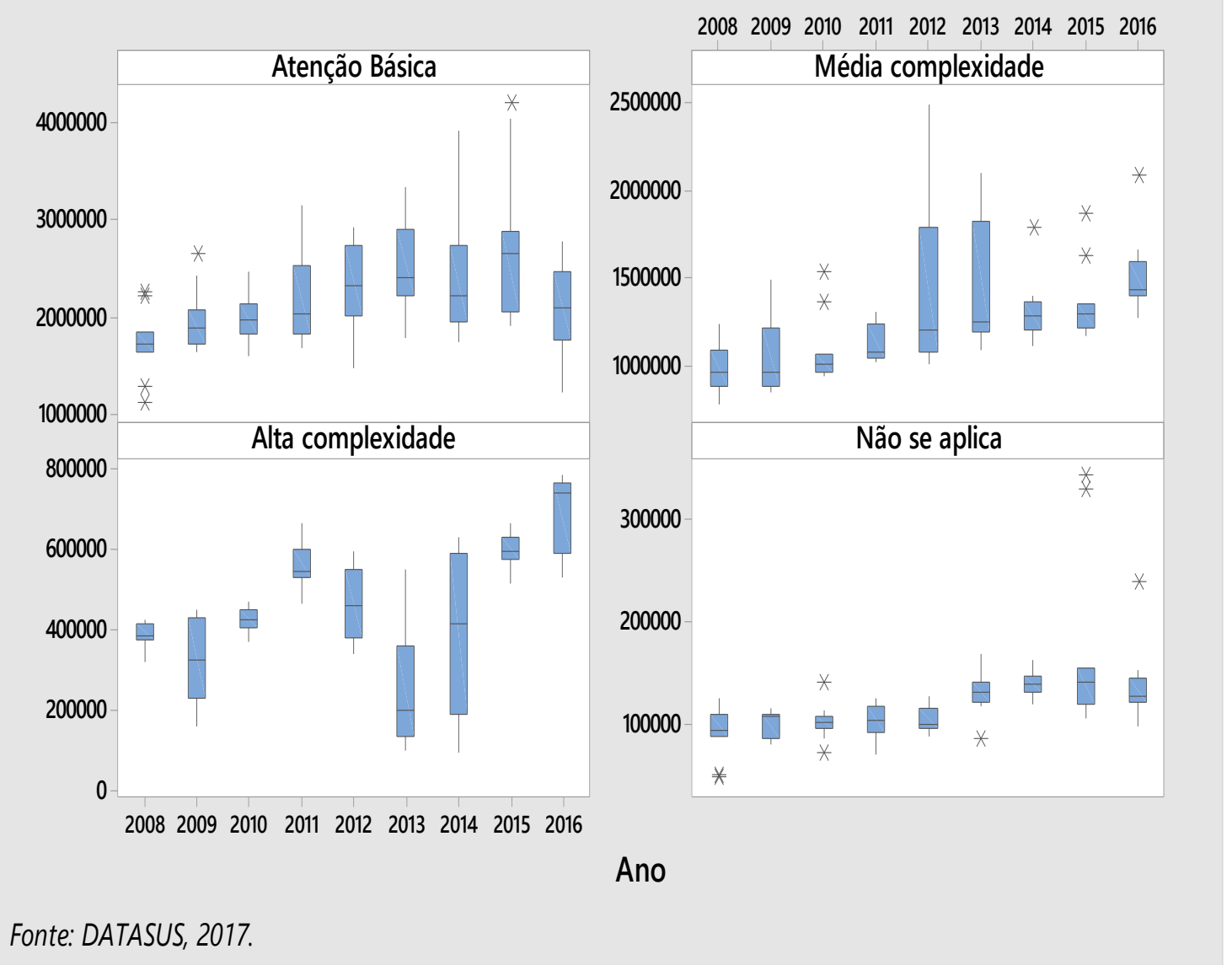

Figura 18. Distribuição da produção ambulatorial apresentada segundo o ano e o nível de complexidade. Dados analisados através do teste Kruskal Wallis (valor $p<0,0001$ ) para cada variável. Fonte: DATASUS, 2017. 


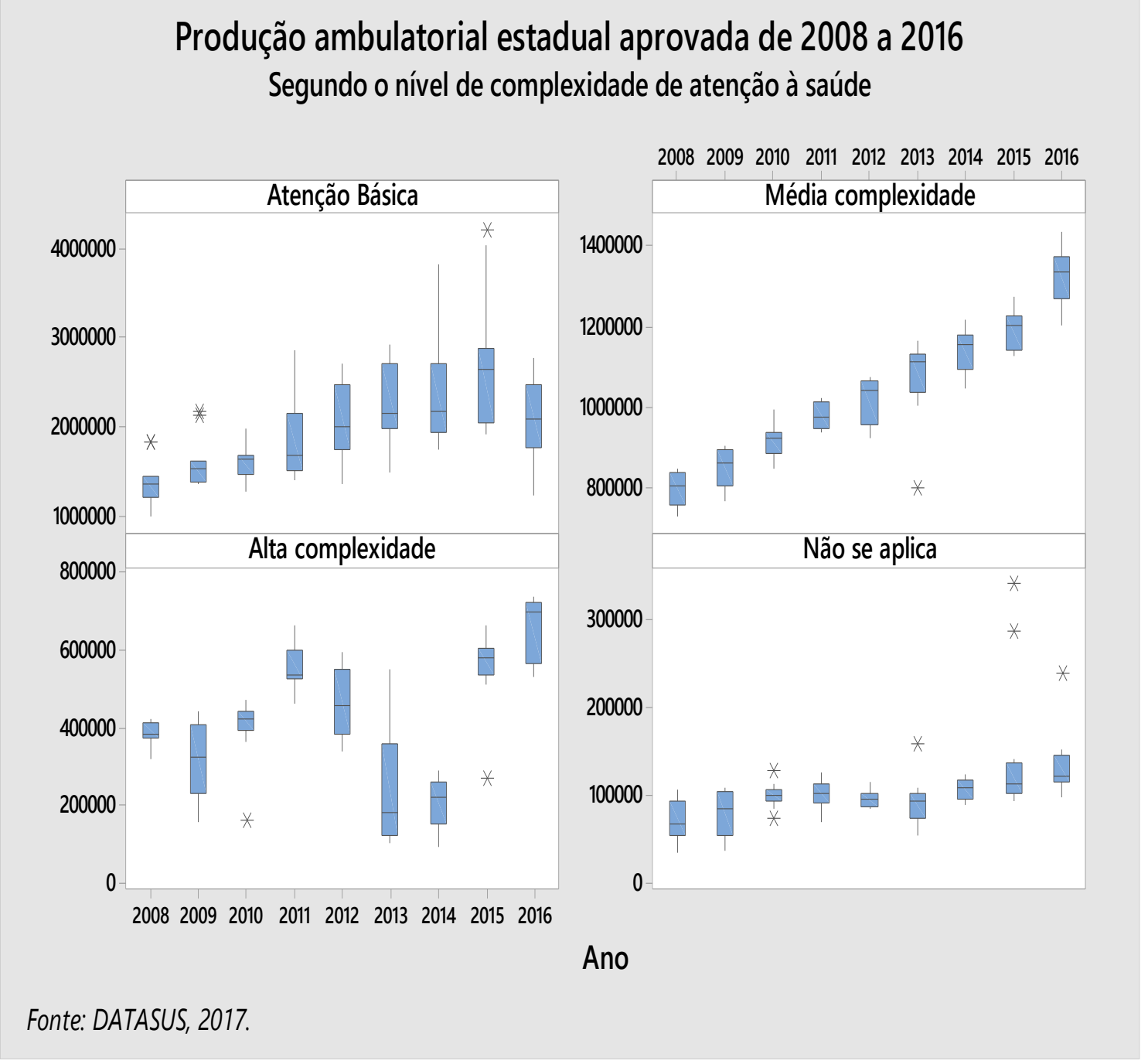

Figura 19. Distribuição da produção ambulatorial aprovada segundo o ano e o nível de complexidade. Dados analisados através do teste Kruskal Wallis (valor $\mathrm{p}<0,0001)$ para cada variável. Fonte: DATASUS, 2017.

\section{Segundo o Colegiado Intergestor Regional (CIR)}

Em relação ao CIR, a maior produção ambulatorial se concentra historicamente no Entre Rios, onde se encontra a capital do estado, Teresina, sendo a produção dos demais colegiados pouco expressiva em comparação ao do Entre Rios em todos os meses do ano e isto é estatisticamente significativo (Figuras 20 a 23). 


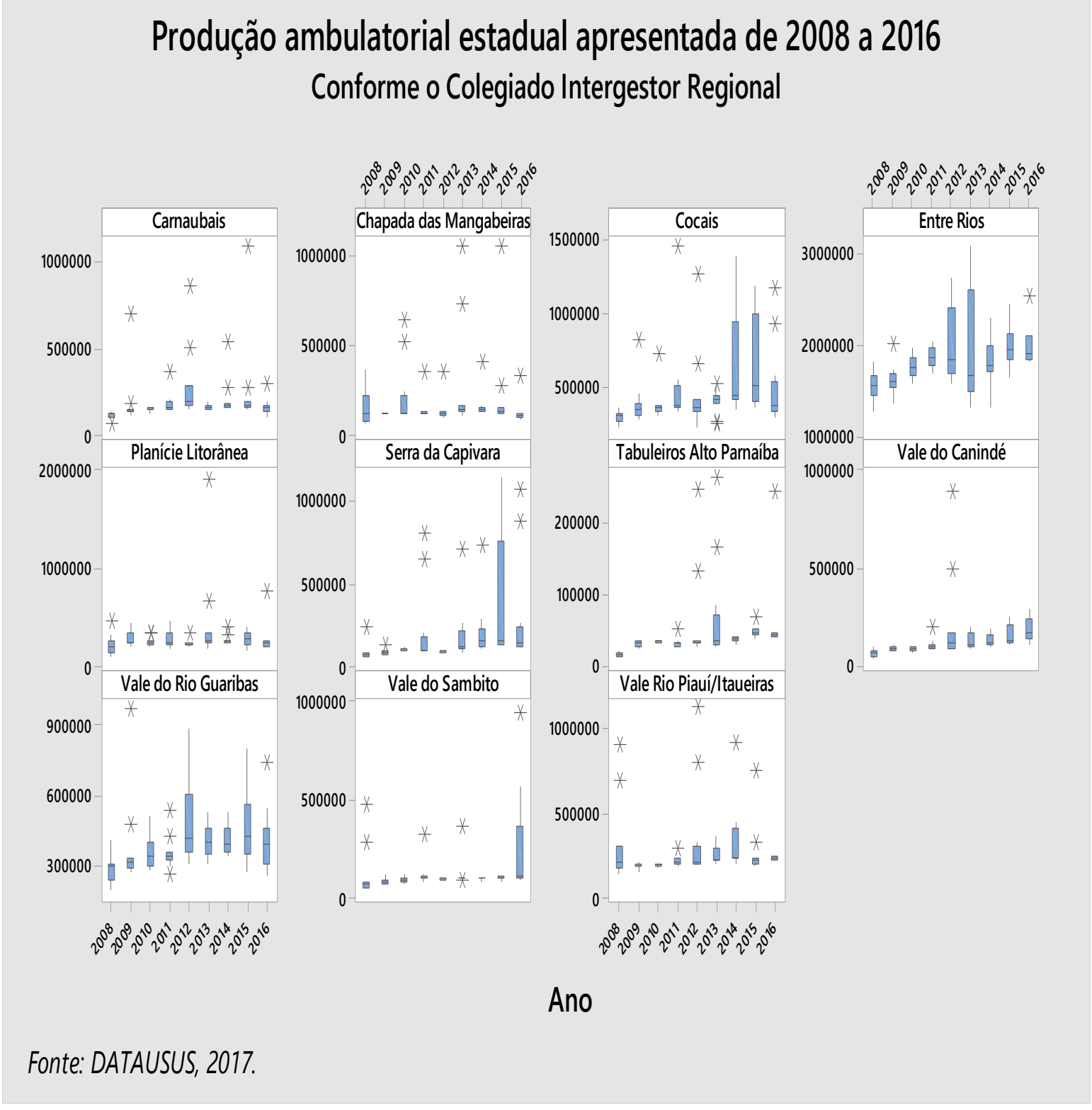

Figura 20. Distribuição da produção ambulatorial apresentada segundo o ano e - Colegiado Intergestor Regional. Dados analisados através do teste Kruskal Wallis (valor $p<0,05$ ) para cada variável. Fonte: DATASUS, 2017. 


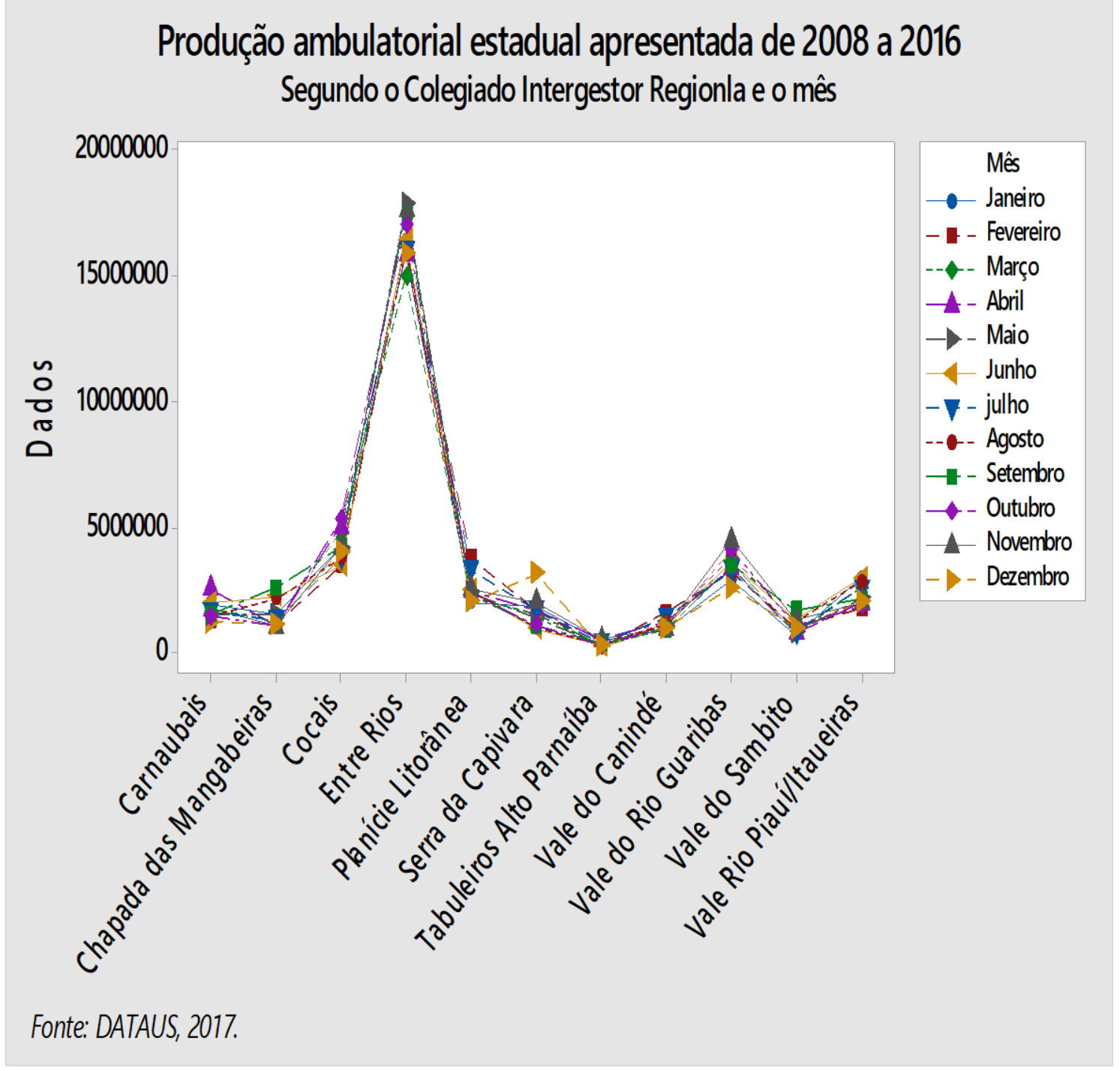

Figura 21. Produção ambulatorial estadual apresentada mensal total de 2008 a 2016 segundo o Colegiado Intergestor Regional. Fonte: DATASUS, 2017. 


\section{Produção ambulatorial estadual aprovada de 2008 a 2016 Conforme o Colegiado Intergestor Regional}

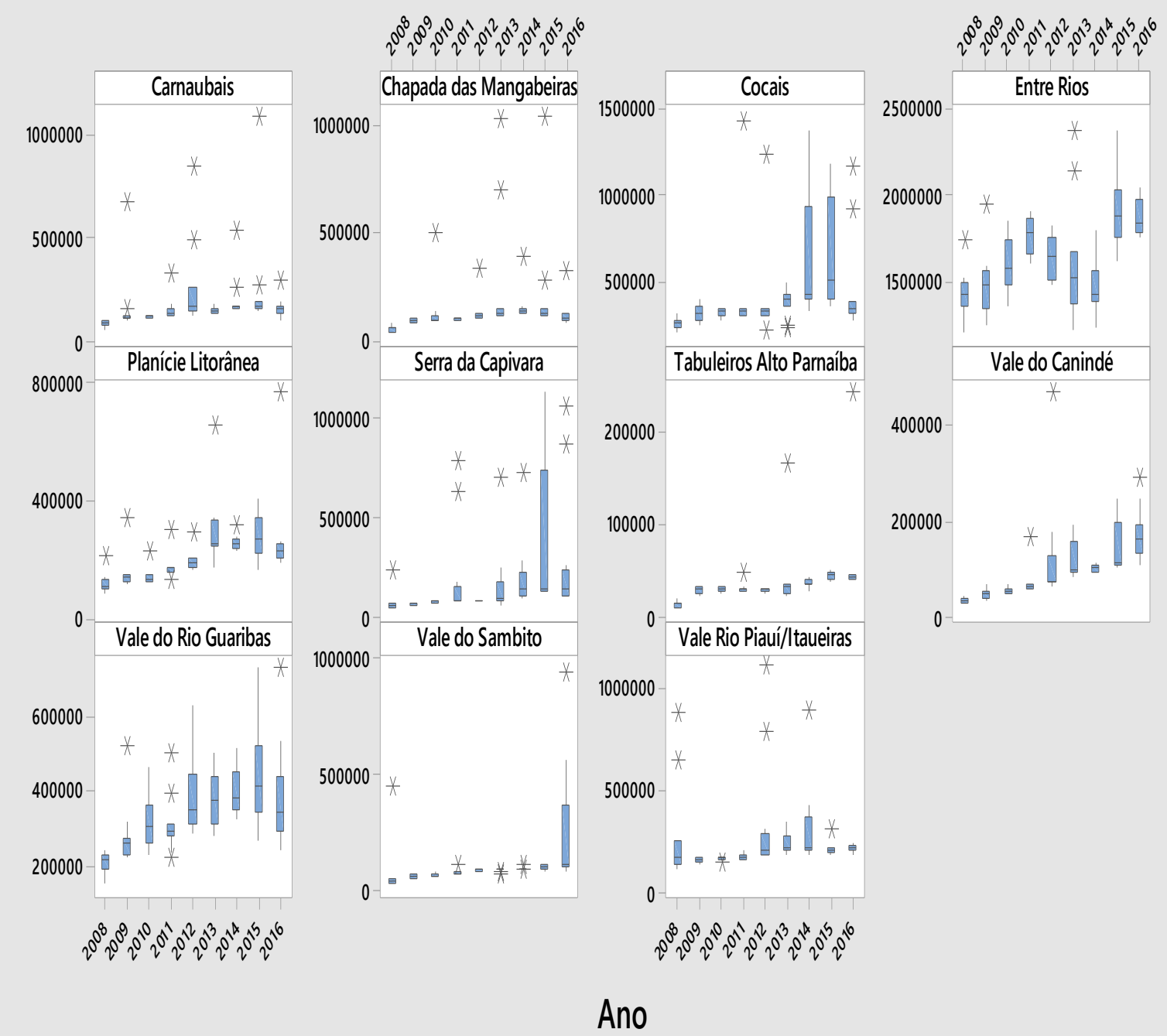

Fonte: DATASUS, 2017.

Figura 22. Distribuição da produção ambulatorial aprovada segundo o ano e o Colegiado Intergestor Regional. Dados analisados através do teste Kruskal Wallis (valor $p<0,0001$ ) para cada variável. Fonte: DATASUS, 2017. 


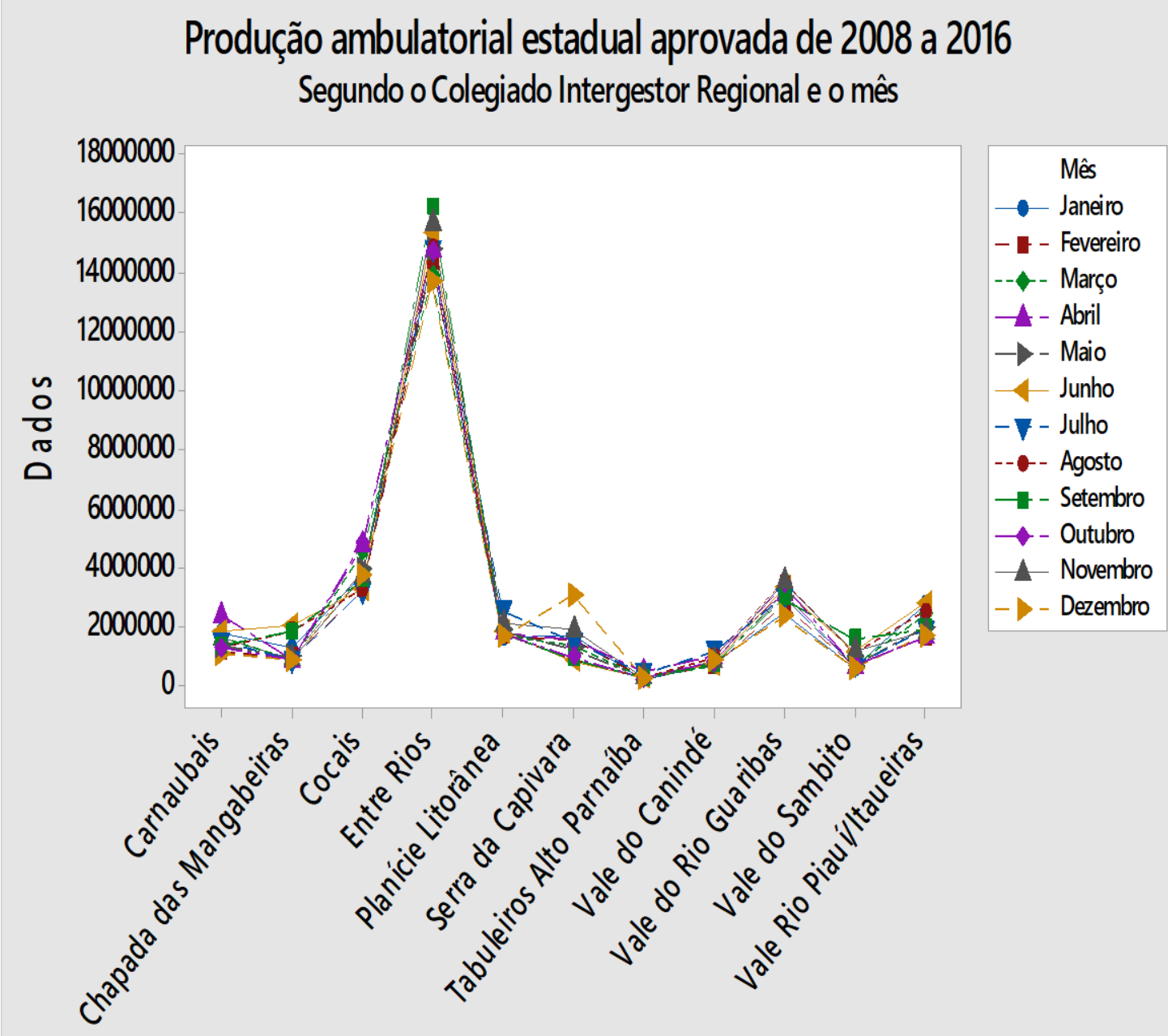

Fonte: DATASUS, 2017.

Figura 23. Produção ambulatorial estadual aprovada mensal total de 2008 a 2016 segundo o Colegiado Intergestor Regional. Fonte: DATASUS, 2017.

\section{DISCUSSÃO}

O financiamento do setor saúde é fundamental para a sustentabilidade da assistência à saúde e componente fundamental tanto para o serviço público quanto para a assistência complementar privada. Uma vez tendo os recursos garantidos, faz-se necessário uma aplicação racional e baseada na produção ambulatorial, hospitalar e nas demais ações em saúde a que competem aos serviços públicos e privados complementares filantrópicos e sem fins lucrativos e contratados ou conveniados ${ }^{1}$.

O serviço público de saúde do Brasil é de acesso universalizado, de assistência integral, hierarquizada e regionalizada, tendo sido seu formato assistencialista e preventista atuais constantes na Carta Magna do Brasil de 1988 nos artigos 198 a 200, tendo sido intitulado como Sistema Único de Saúde. Desde a década de 90 do século passado, várias leis e recursos 
infralegais (portarias, emendas e resoluções) têm sido criados para operacionalizar o SUS, principalmente no que concerne ao financiamento ${ }^{2}$.

As leis orgânicas da saúde (leis 8080 e 8142 de 1990) são os instrumentos primordiais de organização e operacionalização do SUS, definindo os pacotes de investimento, incentivo e gestão. A lei 8080/90 teve seus artigos 31 a 37, que versavam sobre o financiamento do SUS, revogados pela lei 141/2012, exceto pelo $\S 5^{\circ}$ do artigo 32 que estatui sobre assunto diverso de financiamento e o artigo 35 que estabelece critérios para o rateio dos recursos da União ${ }^{2}$.

O artigo 35 da lei 8080/1990 estabelece os valores a serem transferidos a estados, Distrito Federal e municípios através de uma combinação de critérios tais quais a análise técnica de programas e projetos sobre os perfis demográfico e epidemiológico da região, as características da rede de saúde, o desempenho técnico, econômico e financeiro no período anterior, os níveis de participação do setor saúde nos orçamentos estaduais e municipais, a previsão do plano quinquenal de investimentos da rede e ressarcimento do atendimento a serviços prestados para outras esferas de governo ${ }^{2}$.

Segundo a Emenda Constitucional (EC) $n^{\circ}$ 29/2000 que modificou a constituição federal de 1988, os gastos dos governos federal, estaduais e municipais com a saúde puderam ser elevados, garantindo os recursos mínimos para o financiamento dessa área cujos recursos já haviam sido definidos no artigo 198, $\S 1^{\circ}$ : recursos da seguridade social, recursos da união, recursos dos estados, recursos do Distrito Federal, Recursos dos municípios e Recursos de outras fontes (serviços prestados; ajuda, contribuições, doações e donativos; alienações patrimoniais e rendimentos de capital; taxas, multas, emolumentos e preços públicos arrecadados no âmbito do SUS; e, rendas eventuais, inclusive comerciais e industriais) ${ }^{2}$.

Segundo esta EC, a união aplicará o valor empenhado no ano anterior mais, no mínimo, a variação nominal do produto interno bruto, os estados aplicarão 12\% da receita de sua competência, os municípios $15 \%$ da receita de sua competência e o Distrito Federal, 12\% e 15\% das receitas de competências estaduais e municipais, respectivamente ${ }^{2}$.

A lei 141/2012 reafirmou a EC n²9/2000, devendo ser reavaliada a cada cinco ano, conforme determinação constitucional. Outra grande conquista desta lei foi definir quais despesas são consideradas gastos com saúde: aquelas voltadas para a promoção, proteção e recuperação da saúde que sejam de acesso universal, igualitário e gratuito; aquelas que estejam em conformidade com objetivos e metas explicitados nos planos de saúde de cada ente federativo e aquelas que sejam específicas do setor saúde. Portanto, não são despesas do setor saúde, por exemplo, despesas com saneamento básico, merenda escolar, pagamento de aposentadorias e pensões, ações de assistência social, obras de infraestrutura e assistência à saúde não-universalizada² .

O processo de planejamento e orçamento do SUS é etapa essencial para deliberações acerca dos investimentos. Ele depende de estatísticas sobre a produção ambulatorial ou hospitalar os quais são obtidos através dos sistemas 
de informação ambulatorial ou hospitalar (SIA e SIAH) cuja produção é repassada de modo ascendente, isto é, do nível local até o federal, com a participação dos órgãos deliberativos do sistema (colegiados e conselhos), compatibilizando-se as necessidades da política de saúde com a disponibilidade de recursos em planos de saúde das três esferas de governo.

As diretrizes para a elaboração dos planos de saúde são estabelecidas pelo Conselho Nacional de Saúde (CNS) em função das características epidemiológicas e de organização dos serviços de saúde em cada jurisdição administrativa e são, segundo a lei 8142/1990 em seu artigo $4^{\circ}$ um dos requisitos mínimos para que os municípios façam jus ao recebimento de recursos do Fundo Nacional de Saúde (FNS). Além do plano de saúde, são requisitos mínimos para o repasse na modalidade regular e automática a existência de fundo de saúde e de conselho de saúde ${ }^{3}$.

Os conselhos de saúde são órgãos deliberativos existentes em todas as esferas do governo e instrumento de controle social com participação paritária da sociedade ${ }^{4}$.

Caso um município não atenda a algum desses requisitos, os seus recursos de saúde devem ser administrados pelo seu respectivo estado. Por outro lado, se algum estado ou o Distrito Federal não atender a algum dos mesmos requisitos, seus recursos deverão ser administrados pela união ${ }^{2,4}$.

Os recursos federais são repassados em blocos de financiamento cujos componentes são a atenção básica em duas modalidades (pisos fixo e variável), atenção de média e alta complexidade ambulatorial e hospitalar com dois componentes (limite financeiro da média e alta complexidade ambulatorial e hospitalar - MAC - e o componente fundo de ações estratégicas e compensação - FAEC), vigilância em saúde e seus componentes (vigilância e promoção da saúde e vigilância sanitária), assistência farmacêutica e seus componentes (básico, especializado e estratégico), gestão do SUS e seus componentes (qualificação da gestão do SUS e implantação de ações e serviços de saúde) e investimentos na Rede de Serviços de Saúde para realização de despesas de capital mediante projeto encaminhado ao ente federativo ${ }^{2,4,5}$.

O SIA/SUS é um sistema descentralizado utilizado mensalmente pelas secretarias municipais e estaduais de saúde para atualizar as informações sobre estabelecimentos de saúde no sistema SIASUS. A partir do momento da atualização, o sistema SIASUS passa a considerar essas informações para validar o orçamento, importar/digitar a produção, calcular o crédito aos prestadores, emitir os diversos relatórios gerenciais e gerar disquete do Banco de Dados Nacional. Constitui uma ponte entre o cadastro de estabelecimentos em ambiente Windows (CNES) e o aplicativo em ambiente DOS (SIASUS).

O SIA/SUS, por sua vez, é de responsabilidade do Ministério da Saúde (MS), isto é, pela Secretaria de Atenção à Saúde (SAS) no Departamento de Regulação, Avaliação e Controle (DRAC), cuja periodicidade de informação é mensal, estando em funcionamento desde julho de 1994, porém foi criado em 1992 nas Secretarias Estaduais que estavam substituindo os sistemas GAP e 
SICAPS para financiar os atendimentos ambulatoriais. Em 1996, foi largamente implantado nas Secretarias Municipais de Saúde - então chamadas de gestão semiplenas - pela Norma Operacional Básica (NOB) 96. Em 1997 o aplicativo passou a processar além dos tradicionais BPA (Boletim de Produção

Ambulatorial) um documento numerado e autorizado chamado Autorização de Procedimento de Alta Complexidade (APAC) $)^{1,5}$.

O objetivo do SIA/SUS é receber a transcrição de produção nos documentos BPA (Boletim de Produção Ambulatorial) e APAC (Autorização de

Procedimentos de Alta Complexidade, fazer consolidação e validar o pagamento contra parâmetros orçamentários estipulados pelo próprio Gestor de saúde, antes de aprovar o pagamento ${ }^{6}$.

Mensalmente os gestores, além de gerar os valores devidos a sua rede de estabelecimentos, enviam ao DATASUS, uma base de dados contendo a totalidade dos procedimentos realizados em sua gestão. Também mensalmente o DATASUS gera arquivos para tabulação contendo estes atendimentos. Complementando as informações do sistema SIHSUS, fornece ao SAS/DRAC os valores do Teto de Financiamento a serem repassados para os gestores 6 .

Portanto, para que todo o financiamento e transferência de recursos destinados ao teto de financiamento correspondente à atenção ambulatorial, faz-se necessário que o gestor alimente as bases de dados integradas ao DATASUS e que os dados estejam em conformidade para que não haja reprovação da produção e, por conseguinte, o município seja beneficiado com o repasse regular e automático compatível com suas necessidades reais. Para isso, fazse necessária uma gestão eficaz da atenção à saúde ambulatorial e monitorização da produção para minimização das perdas ${ }^{6}$.

\section{CONSIDERAÇÕES FINAIS}

Foi possível constatar eficácia cumulativa na produção ambulatorial em todo o estado do Piauí no período de 2008 a 2016, representada pelas equações com tendência positiva para contas totalmente positivas, porém algumas características adversas puderam ser constatadas, tais quais a maior produção ambulatorial de alta complexidade em detrimento da atenção básica e da média complexidade; a concentração da produção no Colegiado Intergestor Regional do Entre Rios onde se encontra a capital do estado, sugerindo concentração dos investimentos no setor saúde nessa região de saúde; e, o aumento da produção ambulatorial de urgência e por agravos externos, sugerindo serem os gastos em condições emergenciais problemas de saúde pública de relevância gerencial.

\section{REFERÊNCIAS}


1. Coleção Para Entender a Gestão do SUS. A Gestão do SUS.

Brasília: CONASS, 2015.

2. Coleção Para Entender a Gestão do SUS. Assistência de Média e Alta Complexidade no SUS. Brasília: CONASS, 2011.

3. BRASIL. Ministério da Saúde. Curso Básico de Vigilância Epidemiológica. Brasília: Ministério da Saúde, 2005.

4. Ministério da Saúde. Secretaria de Atenção à Saúde.

Departamento de Atenção Básica. Cadernos de Atenção Primária, n. 28, vol. I. Acolhimento à demanda espontânea. Brasília: Ministério da Saúde, 2011.

5. . Ministério da Saúde. Secretaria de Atenção à Saúde. Secretaria de Gestão Estratégica e Participativa. Departamento de Articulação Interfederativa. Cadernos de Informações para a Gestão Interfederativa no SUS. Brasília: Ministério da Saúde, 2012.

6. Ministério da Saúde. O SUS de A a Z: Garantindo Saúde aos Municípios. 3aㅡ ed. Brasília: Ministério da Saúde, 2009.

Recebido: 25 julho 2017. Publicado: 14 agosto 2017

Correspondência: Djalma Ribeiro Costa. E-mail: djalmacosta1@gmail.com

Conflito de Interesses: o autor declara não haver conflito de interesses

(C) This is an Open Access article distributed under the terms of the Creative Commons Attribution License, which permits unrestricted use, distribution, and reproduction in any medium, provided the original work is properly cited 